\title{
Sociedad, identidad y variedad de los mausoleos de La Petaca, Chachapoyas
}

\author{
J. Marla Toyne a y Armando Anzellini ${ }^{\text {b }}$
}

\begin{abstract}
Resumen
Los chachapoya de la sierra nororiental de Perú utilizaron varios métodos para enterrar a sus muertos, pero casi todos estos se dieron en espacios sumamente visibles. Mientras que existe variación regional entre diferentes espacios mortuorios chachapoya, hay evidencia de una cohesión estilística dentro de cada sitio. Desafortunadamente, pocos complejos mortuorios han sido excavados, pero el complejo de La Petaca en el distrito de Leymebamba, nos provee una oportunidad de examinar cientificamente la variación intra-sitio. En solamente medio acantilado del complejo mortuorio registramos un minimo de 125 construcciones incluyendo tumbas, plataformas y caminos, además de cavernas, nichos, y abrigos, todos con restos mortuorios. Utilizando arqueología vertical, recuperamos restos culturales, muestras óseas y orgánicas para análisis bioquimico y para fechados. Desafortunadamente, muchos de los contextos han sido dañados por la actividad de los huaqueros y los procesos tafonómicos naturales. Se ha hallado variabilidad en los métodos constructivos, materiales, diseños arquitectónicos y ubicación en el sitio, pero en general la distribución de rasgos comunes sugiere varias interpretaciones: 1) el estilo mortuorio fue adaptado a la locación precaria, 2) habia muy pocos cambios a través del tiempo, 3) habia pocos constructores de estas tumbas, o 4) este complejo refleja patrones constructivos de una sola tradición. Sobre todo, estos datos nuevos nos pueden presentar valiosas interpretaciones sobre la accesibilidad, la complejidad en construcción y aspectos de la identidad social de los chachapoya.
\end{abstract}

Palabras clave: arqueología vertical, arquitectura mortuoria, prácticas funerarias, complejidad social, tumbas, Chachapoyas

\section{Abstract}

\section{SOCIETY, IDENTITY AND VARLATION IN THE LA PETACA MAUSOLEUMS, CHACHAPOYAS}

The Chachapoya of the northeastern Peruvian highlands utilized various methods for disposing of their dead, but almost all involve highly visible spaces. While some regional variation is found among Chachapoya mortuary spaces, there is evidence for social cohesion within each site. While few mortuary complexes of the Chachapoya have been excavated, La Petaca mortuary complex in the Leymebamba district, provides the opportunity to scientifically study intrasite variation. On only half of the mortuary complex's massive vertical wall we documented 125 constructions including tombs, platforms and walkways, as well as several caves, niches and rock shelters, all of which contained mortuary remains. By using techniques of vertical archaeology, we collected artifacts and skeletal and organic samples for analysis and radiocarbon dating. Unfortunately, many of the contexts had been damaged by looting and natural taphonomic processes. There was some variability in construction methods, materials, architectural design, and location across the site, yet generally common features suggest several interpretations: 1) mortuary style was adapted to the precarious location, 2) there was little change over time, 3) few builders were involved, or 4) these practices reflect a single cultural tradition. Overall, these new, detailed data yield valuable information on the importance of mortuary spaces and the regional complexity of the Chachapoya.

Keywords: vertical archaeology, mortuary architecture, funerary practices, social complexity, tombs, Chachapoya

${ }^{a}$ University of Central Florida

Correo electrónico: j.marla.toyne@ucf.edu

${ }^{\mathrm{b}}$ University of Central Florida

Correo electrónico: armando.anzellini@knights.ucf.edu 


\section{Introducción}

En todos los Andes, estudios sobre los restos mortuorios arqueológicos han demostrado una conexión importante entre prácticas culturales, identidad y elaboración de tumbas (Reichlen y Reichlen 1950; Dillehay 1995; Isbell 1997; von Hagen y Guillén 1998; Kamp 1998; Arriaza et al. 2005; Kauffmann Doig y Ligabue 2003; Guillén et al. 2011; Velasco 2014). Las prácticas mortuorias de los chachapoya han sido de mucho interés para los andinistas debido a su variabilidad, modo de fabricación y su ubicación en sitios difíciles de acceder, en acantilados impresionantemente altos (Muscutt 1998; Ruiz Estrada 2009; Crandall 2012). La variación mortuoria y su relación con la expresión de la organización sociopolítica en Chachapoyas es poco conocida. Mientras que existe una gran variedad de elaboración, la cual sugiere una jerarquía con élites sociales (cf. Tainter 1978), la evidencia arqueológica y arquitectónica en los centros residenciales todavía no ha sido definida en su totalidad (Guengerich 2014). Estudios bioarqueológicos que busquen indicadores óseos de diferenciación social dentro de estos contextos, proveerán información adicional para responder estas preguntas (ver Toyne y Narváez en este número). Además, existe poca evidencia que indique si esta variación en la complejidad de las tumbas es debido a un cambio de estilo y técnica a través del tiempo, o una evolución cultural hacia la complejidad social de esta región. Pocos complejos mortuorios de los chachapoya han sido excavados de forma científica ya que muchos han sido saqueados y disturbados durante los años. A pesar de esto, el complejo mortuorio de La Petaca, en el distrito de Leymebamba, nos da la oportunidad de investigar el alcance de la variación dentro de un solo sitio arqueológico.

Los antiguos chachapoya utilizaron varios métodos de enterrar a sus muertos incluyendo la colocación de los restos debajo de los pisos en casas, dentro de las construcciones como muros y plataformas, y, lo más impresionante de todo, en tumbas encima de repisas angostas de paredes rocosas (Morales Gamarra 2002; Kauffmann Doig y Ligabue 2003; Ruiz Estrada 2009). Las estructuras de entierro en sitios verticales son sumamente variadas, pero pueden ser clasificadas en dos categorías principales: sarcófagos individuales y mausoleos colectivos. Pareciera existir un patrón en el cual los sarcófagos se encuentran en el ámbito norte de la región y las tumbas grandes construidas en piedra, son más frecuentes en el sur (Nystrom et al. 2010). Fuera de Kuélap, no existe un sitio arqueológico donde ambos estilos estén presentes. Mientras que muchos sitios han sido reconocidos a través de fotografías (Muscutt 1998; Kauffmann Doig y Ligabue 2003), su estudio científico está recién comenzando (Church y von Hagen 2008). Desafortunadamente, el saqueo de sitios arqueológicos es demasiado común y muchos de estos sitios han sido disturbados, especialmente los sitios visibles y de fácil acceso. Sin embargo, creemos que una gran cantidad de información valiosa se puede recuperar de un análisis de los restos arquitectónicos, culturales y óseos que quedan, para así entender mejor la naturaleza de esta variación y las historias ocupacionales de estos sitios mortuorios. En este artículo, presentamos un resumen del sitio de La Petaca y describimos los resultados de nuestra investigación preliminar.

Uno de los temas de investigación más valiosos es la relación entre la accesibilidad restringida, la complejidad constructiva y la identidad social. ¿Por qué usar estos espacios verticales, los cuales son difíciles de acceder, para enterrar a sus difuntos? ¿Sirvió la inaccesibilidad como método de restringir el acceso a un grupo exclusivo de la comunidad? ¿Fue la visibilidad de estas estructuras esencial para su significado social? Existen otros entierros que ocurren dentro de cavernas más fáciles de acceder o en tumbas dentro de complejos residenciales. Por lo tanto, hay un nivel adicional de complejidad y dificultad al construir estas tumbas en lo alto de acantilados angostos. ¿Cuál fue la intención de los componentes arquitectónicos al demostrar o reforzar la identidad social de aquellos enterrados ahí? En las tumbas colectivas, los mensajes codificados en su construcción sobrepasan la identidad del individuo, pudiendo referirse a unidades de linajes familiares o comunitarias (Hastorf 2003; Mantha 2009). El análisis de las interacciones en la región de Chachapoyas durante el periodo histórico temprano conducido por Espinoza Soriano (1967: 246) sugiere que las tumbas en los acantilados y abrigos rocosos fueron los lugares preferidos por las élites sociales y sus linajes; por 
ello, nuestro objetivo es entender cómo la arquitectura, la ubicación y los materiales constructivos en los lugares de entierro, estuvieron relacionados a la complejidad social de estos grupos.

El sitio arqueológico de La Petaca es ideal para explorar estas preguntas, ya que es uno de los sitios mortuorios más grandes hasta ahora estudiados en Chachapoyas. Con cientos de estructuras esparcidas sobre 12.000 metros cuadrados de roca expuesta, y una ocupación que abarca casi 600 años - lo cual sabemos sobre la base de un grupo de fechas radiocarbónicas-, exploramos el panorama del sitio utilizando una selección de tumbas para identificar la variación arquitectónica (métodos de construcción, materiales, decoraciones, y tamaño) y sus contenidos culturales y óseos, para así poder discutir las implicaciones de esta variación y su relación con el ambiente, la cronología y la complejidad social.

Iniciamos nuestra exploración con estos datos con la intensión de contribuir a la discusión antropológica sobre cómo las prácticas y estructuras funerarias funcionan como espacios activos para la intersección de la cultura, el poder y la organización social en las sociedades antiguas (Lefebvre 1991; Moore 1996; Arriaza et al. 2005; Herrera 2005).

\section{La arquitectura mortuoria de los chachapoya y la complejidad social}

La exploración de prácticas y espacios mortuorios puede ayudarnos a dar un vistazo a la intersección de las creencias y la complejidad social (Binford 1971; Brown 1971; Carr 1995). La construcción de espacios mortuorios (v.g. tumbas, monumentos), la disposición de los cuerpos y el simbolismo de la iconografía y arquitectura, funcionan como señales de identidad cultural, estatus, y hasta agencia individual (Parker Pearson y Richards 1994; Moore 1996; Lovell 1998; Herrera 2005; 2007; Mantha 2009). Mientras que la agencia es difícil de estudiar en el registro arqueológico, las características más comunes y los patrones en la construcción encontrados en los edificios significativos, sugieren una identidad cultural común, reflejada en estos espacios sagrados. Al examinar la complejidad en elaboración, la "teoría de la inversión» sugiere que costos laborales mayores en la construcción de una tumba, indican el prestigio social del individuo enterrado (Saxe 1971; Tainter 1978; Abrams 1989). Por eso, una estructura mortuoria, que requiere más inversión material y de trabajo, indica el entierro de un individuo, o linaje, de un mayor estatus social.

En Chachapoyas, algunas investigaciones arqueológicas se han enfocado principalmente en restos mortuorios, incluyendo las tumbas de alta visibilidad (Gil 1936; Reichlen y Reichlen 1950; Jakobsen et al. 1986-87; Kauffmann Doig y Ligabue 2003; Briceño y Muscutt 2004; Koschmieder y Gaither 2010; Ruiz Estrada 2009). Investigaciones de sitios mortuorios específicos, como Los Pinchudos, Revash y Karajía, han creado una multitud de preguntas sobre la estructura sociopolítica y la filiación cultural de los antiguos chachapoya (Bracamonte 2002; Morales Gamarra 2002; Nystrom et al. 2010). El rango de complejidad hallada en estos sitios arqueológicos, desde mausoleos intrincados y muy decorados en Los Pinchudos, a construcciones más uniformes en Revash, y hasta sarcófagos individuales en Karajía, ha llevado a algunos investigadores a sugerir que los chachapoya no poseían una identidad cultural unificada. Compartían símbolos y cultura material, pero no eran una entidad política única hasta la unificación causada por la invasión de los inkas (Church y von Hagen 2008).

Uno de los sitios mortuorios más reconocidos en esta región es la laguna de los Cóndores. El descubrimiento de este sitio y sus cientos de fardos funerarios ha añadido una gran cantidad de información a nuestro conocimiento de las prácticas funerarias de los chachapoya, además de la cosmovisión andina en su totalidad (Urton 2001; Guillén 2002; von Hagen 2002). Las tumbas de los chachapoya claramente fueron construidas con la expectativa de acceso continuo a los restos y con suficiente espacio para sugerir la posibilidad de enterramientos sucesivos, a través de las generaciones dentro del mismo espacio sagrado (Dillehay 1995; Isbell 1997; Nystrom et al. 2010). Las investigaciones de Salomon $(1995,2015)$ sugieren que el tamaño de la tumba y su ubicación funcionaban solo con relación a ritos mortuorios continuos en los cuales los restos se acumulaban, 
pero también las visitas frecuentes transformaban las ofrendas, creando una historia deposicional compleja. Por eso, tumbas colectivas de reuso y revisita requieren que esos espacios sean accesibles. La Petaca es un sitio mortuorio único debido a su tamaño y número de estructuras, haciéndolo una adición inestimable a la literatura de las prácticas mortuorias de los chachapoya.

\subsection{El sitio arqueológico}

El sitio de La Petaca, ubicado 14 kilómetros al suroeste del pueblo moderno de Leymebamba, es un complejo mortuorio con cientos de estructuras construidas sobre una inmensa pared vertical de roca expuesta (Figs. 1 y 2). La zona con restos mortuorios que conforma el sitio de La Petaca mide aproximadamente 500 por 100 metros y está localizada a cerca de 250 metros de altitud sobre el valle. Mientras que algunas áreas tienen vegetación adherida a la roca del acantilado, las tumbas solo se encuentran en los espacios de roca expuesta. Desafortunadamente, muchos de los contextos son muy difíciles de acceder y la mayoría han sido dañados por el saqueo y por procesos tafonómicos naturales —incluyendo la misma fragilidad del substrato de la roca misma-. Este sitio representa el complejo mortuorio más grande hasta hoy estudiado, pero nunca ha sido descrito o investigado en detalle, pese a ser reconocido en la región por su arte rupestre (Muscutt 1998; Kauffmann Doig y Ligabue 2003).

\section{Objetivos y métodos de la investigación}

Los objetivos del Proyecto Arqueológico de La Petaca (PALP) incluyeron: 1) probar nuestra habilidad de mapear las estructuras en estos espacios de difícil acceso (creando un mapa de la distribución vertical); 2) la excavación e investigación de una muestra de las estructuras con mayor detalle para comprender su construcción y uso; y 3) la recuperación de material orgánico para el análisis de radiocarbono e isótopos estables, con el objetivo de mejorar nuestro conocimiento de la cronología y ocupación del sitio. Creamos un método innovador de arqueología vertical para acceder, documentar y recolectar los restos culturales, óseos y orgánicos para nuestro análisis. Sin el apoyo de los técnicos especialistas, utilizando métodos de progresión vertical (rappel y ascensión) para ascender a los acantilados angostos donde estas tumbas se ubicaban, no hubiéramos podido examinar y documentar estas estructuras (Fig. 3). El mapeo sistemático y la fotografía nos permitieron observar 125 estructuras, de las cuales 76 fueron identificadas por su función general (mortuoria [tumbas], transitoria [caminos], y estructural [plataformas]). La meta general era determinar la gama de variación en construcción mortuoria y recuperar datos sistemáticos de los contextos que quedaban. Esperábamos que la variación en el diseño arquitectónico fuera limitada debido a los límites físicos del ambiente, y sobre todo si estas estructuras fueron creadas por una comunidad unificada durante un periodo de tiempo limitado. Si estas estructuras fueron usadas durante un periodo de tiempo extendido, entonces a lo mejor la variación reflejaría la idiosincrasia de cambios históricos en método e ideas. Pero esta variación también podría reflejar la habilidad del constructor o la preferencia del individuo, influenciada por la identidad social y la necesidad de expresar diferencias en estatus. Podría ser difícil distinguir entre estas opciones, pero reconocemos que la creación de estos espacios mortuorios formaba solo una parte del uso y función del espacio, el cual probablemente incluía ritos complejos inmateriales y simbolismo que no puede ser recuperado en el registro arqueológico.

\section{Resultados}

Hemos identificados seis categorías principales de contextos funerarios y estructuras, basadas en nuestras observaciones, las cuales pueden ser divididas entre contextos naturales (cavernas, abrigos, y nichos) (Figs. 4 y 5) y espacios construidos (tumbas colectivas, chullpas y mausoleos) (Figs. 6 a 8). 


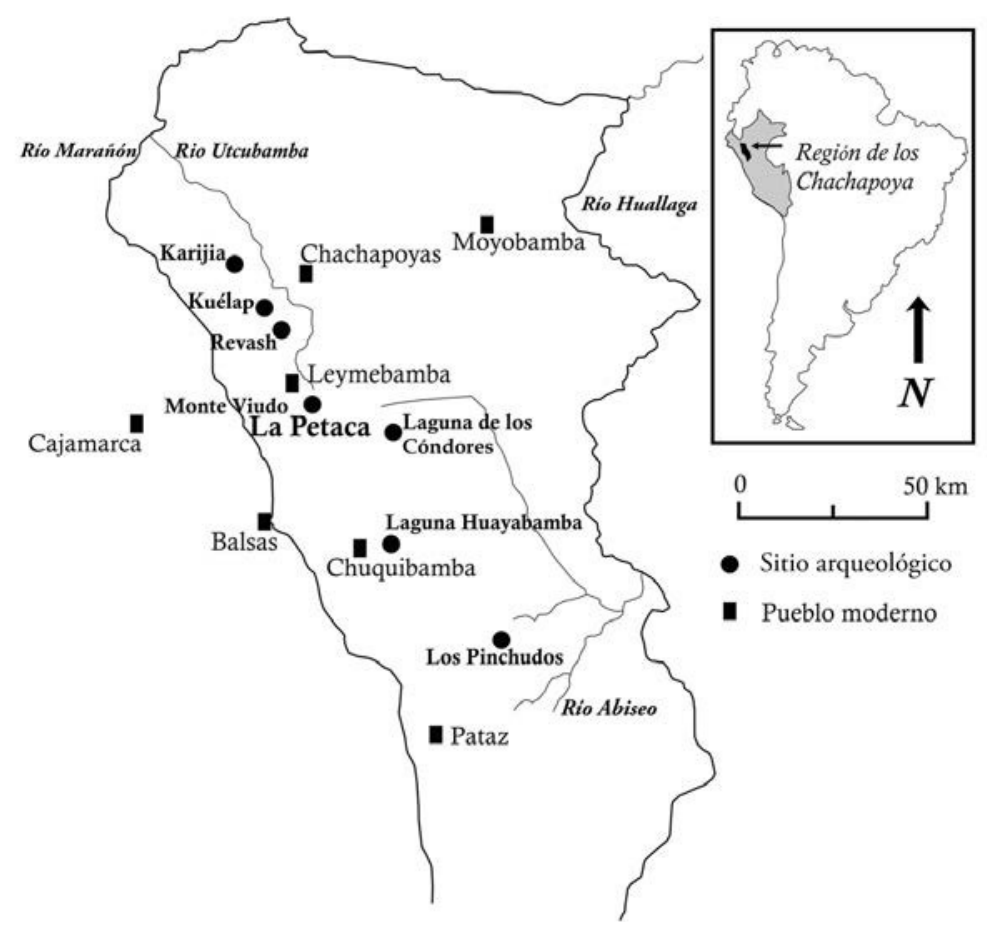

Figura 1. Mapa de la ubicación del sitio (por Nystrom et al. 2010).

Las tumbas colectivas frecuentemente se encuentran en forma de "colmena», son de tamaño medio (entre 1 a 2 metros), construidas alrededor de un conjunto de cuerpos. De estas solamente queda la impronta de paredes circulares bajas. Las chullpas colectivas son construcciones más grandes y rectangulares, las cuales consisten en una cámara abierta construida encima de una plataforma artificial preparada y elevada sobre la repisa natural (Fig. 6). Los mausoleos colectivos son estructuras grandes, con cámaras abiertas que fueron construidas directamente sobre la repisa natural y muchas veces consisten en dos niveles constructivos (Fig. 7). La diferencia entre las chullpas y los mausoleos es la presencia de una plataforma constructiva como base en las chullpas, y la construcción de una banqueta de vigas de madera en los mausoleos. Todos estos espacios son entierros colectivos que incluyen los restos de múltiples individuos. En La Petaca, no se encuentra evidencia de estructuras individuales como los sarcófagos, entierros en fosas, o tumbas personales. La Tabla 1 presenta una descripción de estas categorías como se encuentran en cada sector. Además de estos espacios construidos y modificados, se encuentra evidencia de pintura roja en la piedra natural asociada con tumbas específicas. La pintura generalmente toma la forma de una banda rectangular o de «U» invertida (Fig. 9), pero también se encuentran varios ejemplos de representaciones antropomórficas y zoomórficas. En muchos de los casos, estas salpicaduras grandes de color rojo fueron distinguibles a larga distancia, y de seguro representan un simbolismo significativo, marcando este espacio como un sitio sagrado y funerario. Los restos arqueológicos consistieron en su mayoría, en restos humanos con muy poca cerámica u otro material cultural, pero sí se recuperaron fragmentos de mates, herramientas líticas, adornos personales, cuentas de concha y textiles (González Valencia y Toyne 2014). Es difícil determinar si la escasez de materiales culturales sea el resultado del saqueo o de la falta de ofrendas enterradas con estos individuos. Por lo tanto, aquí no presentamos un análisis de los escasos restos culturales encontrados dentro de las estructuras. 


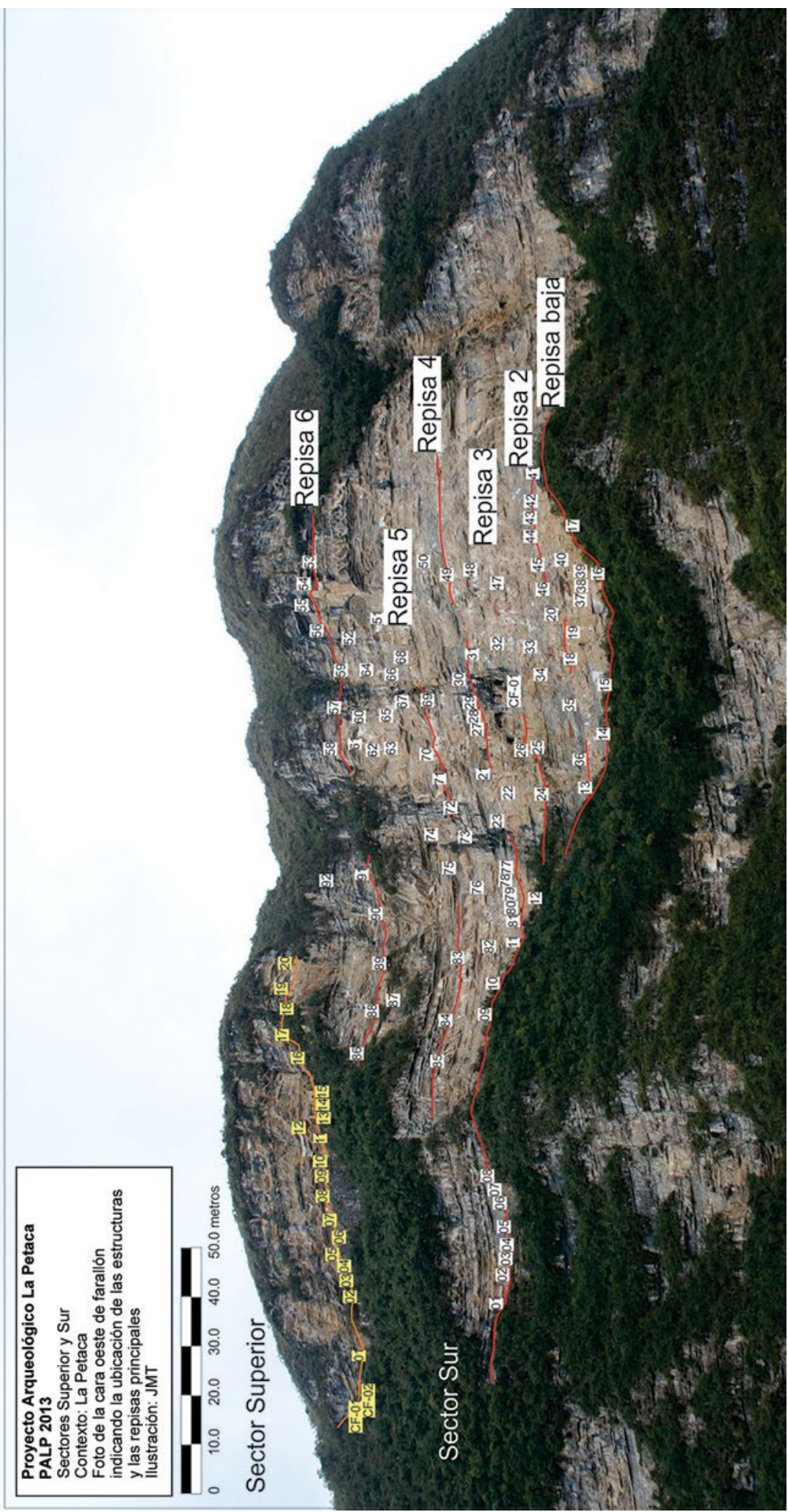

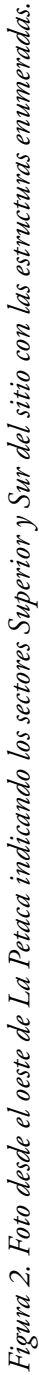




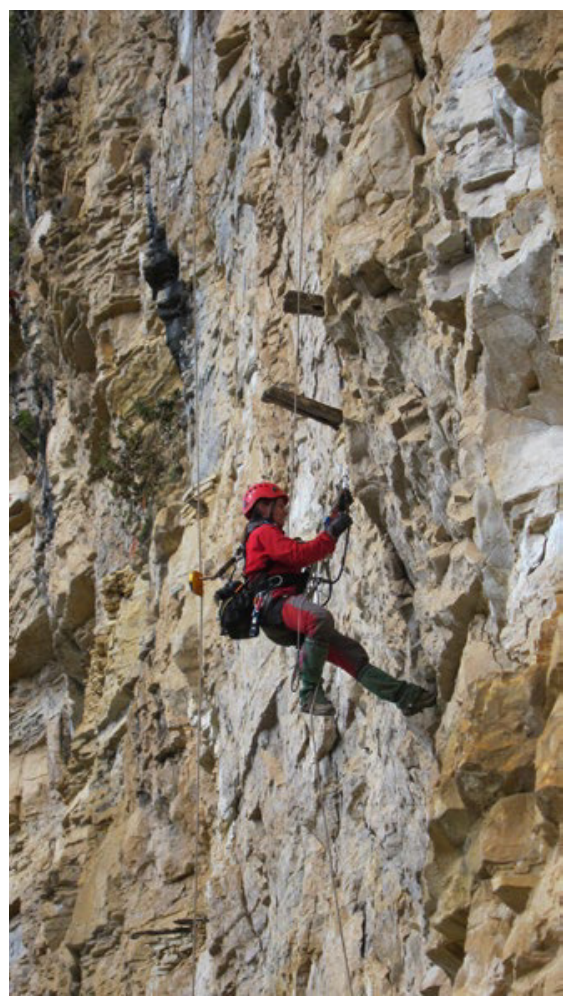

Figura 3. Foto de la doctora Toyne ascendiendo a las plataformas superiores utilizando las técnicas de progresión vertical.

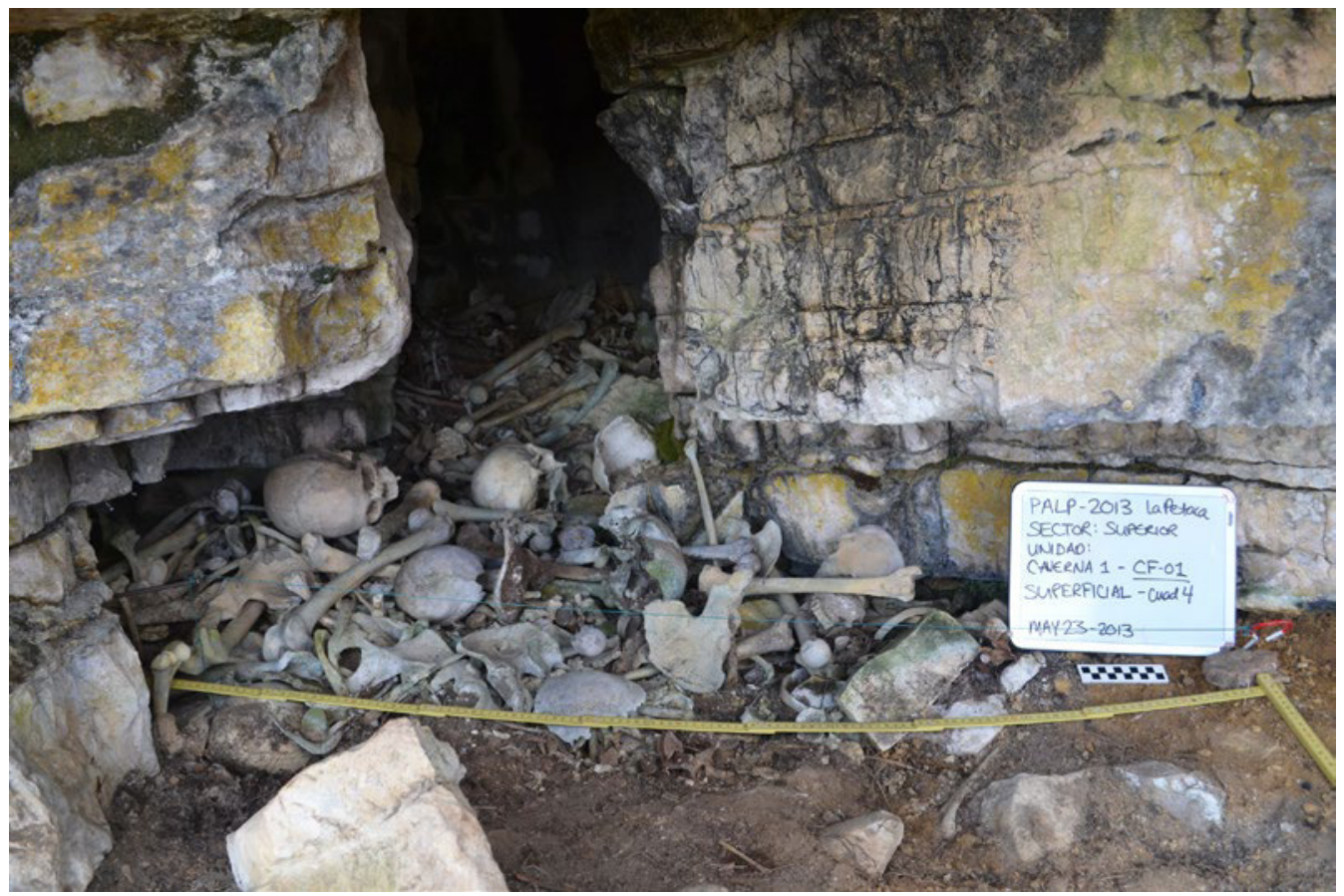

Figura 4. Foto del vano de acceso de la estructura Sup CF-O1 antes de las excavaciones. 


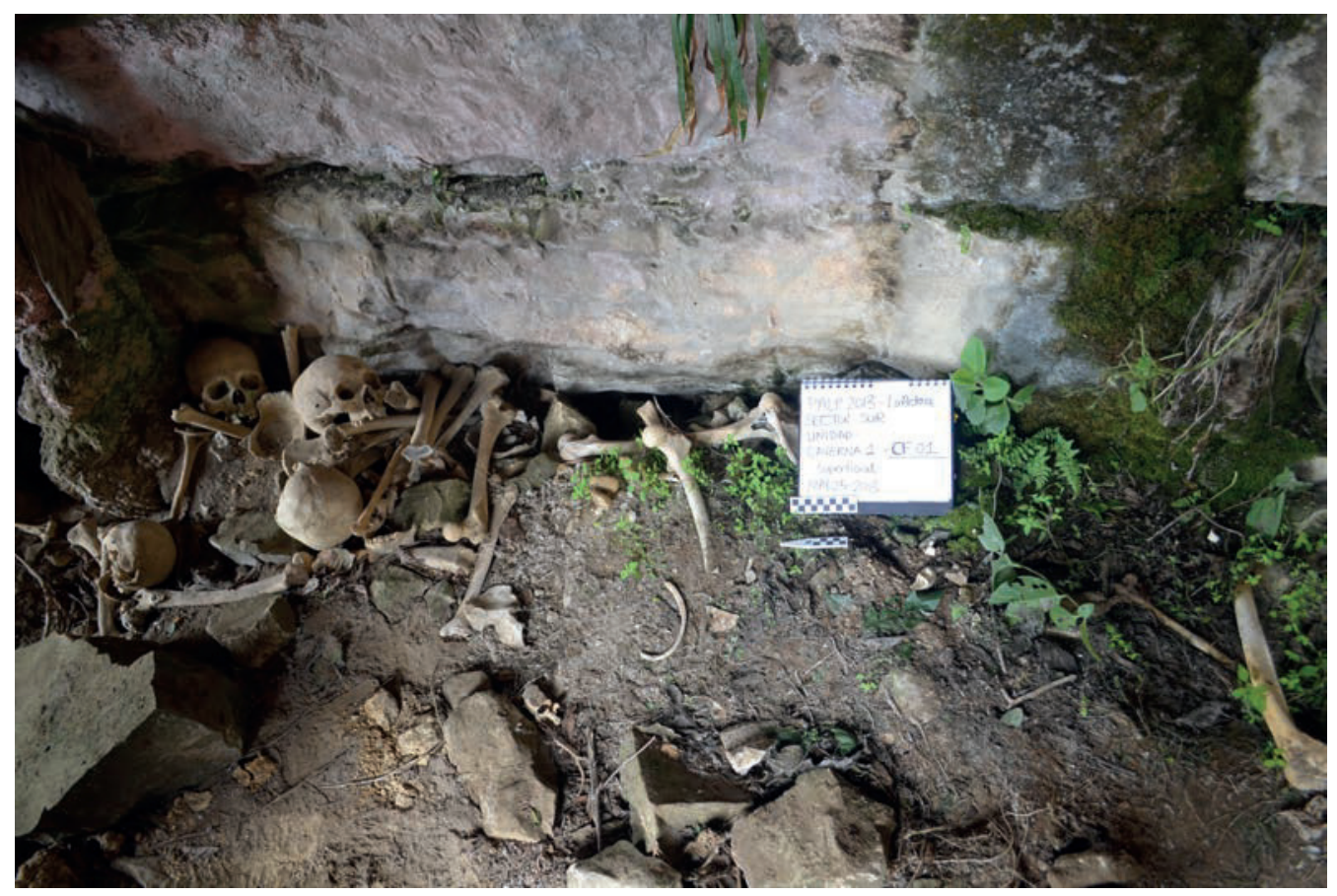

Figura 5. Foto de la caverna mortuoria Sur CF-O1 con evidencia de concentraciones de restos óseos humanos.

\subsection{Tafonomía}

La tafonomía natural de la escarpadura ha creado un ambiente muy específico, el cual afectó las condiciones de los restos arqueológicos que observamos y recuperamos. En general, la preservación de la arquitectura y el material arqueológico va desde muy pobre hasta excelente, debido a una gran variedad de factores incluyendo la geología, los procesos tectónicos, el microclima del sitio, la actividad animal y la acción humana. La escarpadura consiste en piedra caliza sedimentaria, formada por estratos naturales y angostos. Este tipo de piedra tiende a fragmentarse fácilmente, lo cual facilitó la formación de las repisas naturales sobre las cuales se construyeron estas estructuras. Sin embargo, los estratos geológicos también son frágiles y se pueden fragmentar bajo diferentes tipos de presión.

Aunque el nivel de precipitación es alto en toda la región, el contorno cóncavo de esta pared crea una saliente que protege las estructuras del impacto directo de las lluvias. Esto creó un ambiente seco que ayudó a la preservación del material orgánico como textiles, cuerdas de fibra y restos humanos desecados. Otros sitios en la región, como la laguna de Los Cóndores, nos indican que era posible encontrar materiales arqueológicos bien preservados en La Petaca antes de que los cambios naturales y antropogénicos afectaran al sitio. La vegetación que se introdujo en las superficies angostas horizontales también puede haber protegido el material al absorber la humedad, pero el sistema de raíces también contribuyó a la separación de la piedra, lo cual dañó los restos arqueológicos.

Estos acantilados también son espacios naturales llenos de diferentes tipos de animales incluyendo aves (un par de águilas anidando estuvieron presentes durante nuestra visita sobre una estructura media desmontada por su nido), zorros, venados y varios roedores. Las cavernas mismas también forman hogares para los murciélagos y aves pequeñas. La presencia y actividad de estos animales resultó en depósitos de sus heces y restos óseos en las repisas y dentro de las estructuras. Claramente su presencia afectó el contexto original de varias maneras y se observa daño directo en los restos humanos, incluyendo marcas de mordisqueo en los huesos. Las aves grandes que anidan 

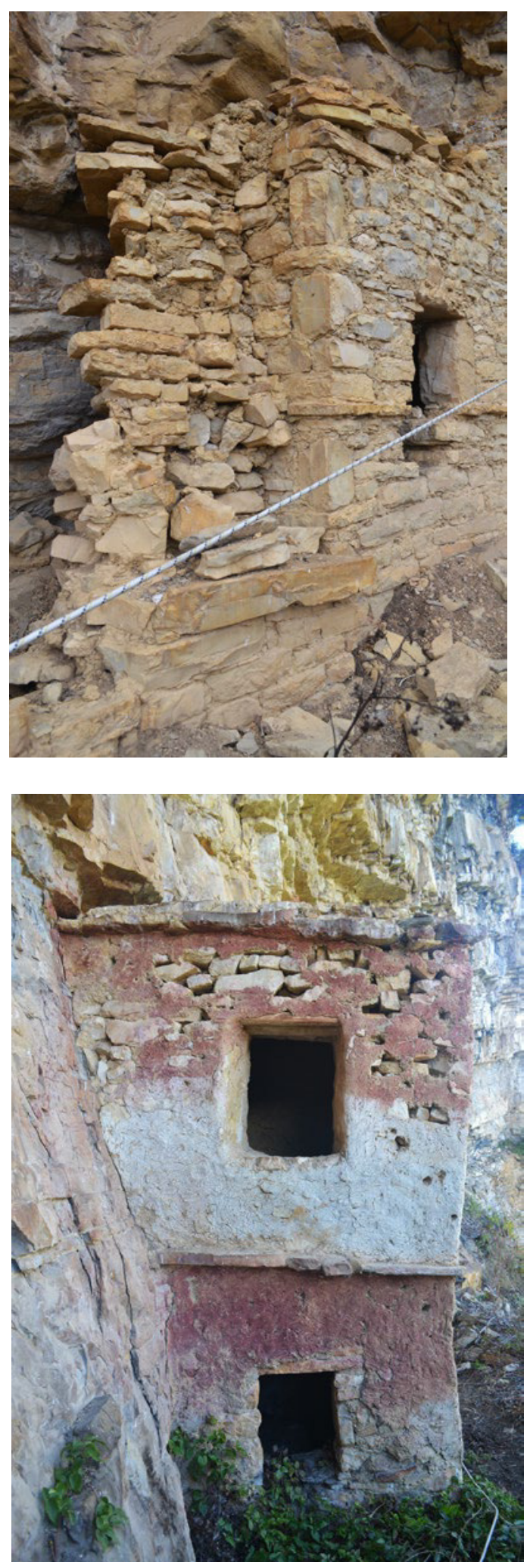

Figura 6. Foto del mausoleo Sup EF-14 (izquierda, con albañilería de pobre organización) y chullpa Sup EF-15 (derecha, con albañilería de mejor calidad) mostrando técnicas constructivas diferentes en tumbas adyacentes.

Figura 7. Foto de Sur EF-01, un mausoleo bien conservado, el exterior con acabado de mortero y pintura blanca sobre rojo de dos pisos (vista desde el norte de los dos vanos de acceso). 


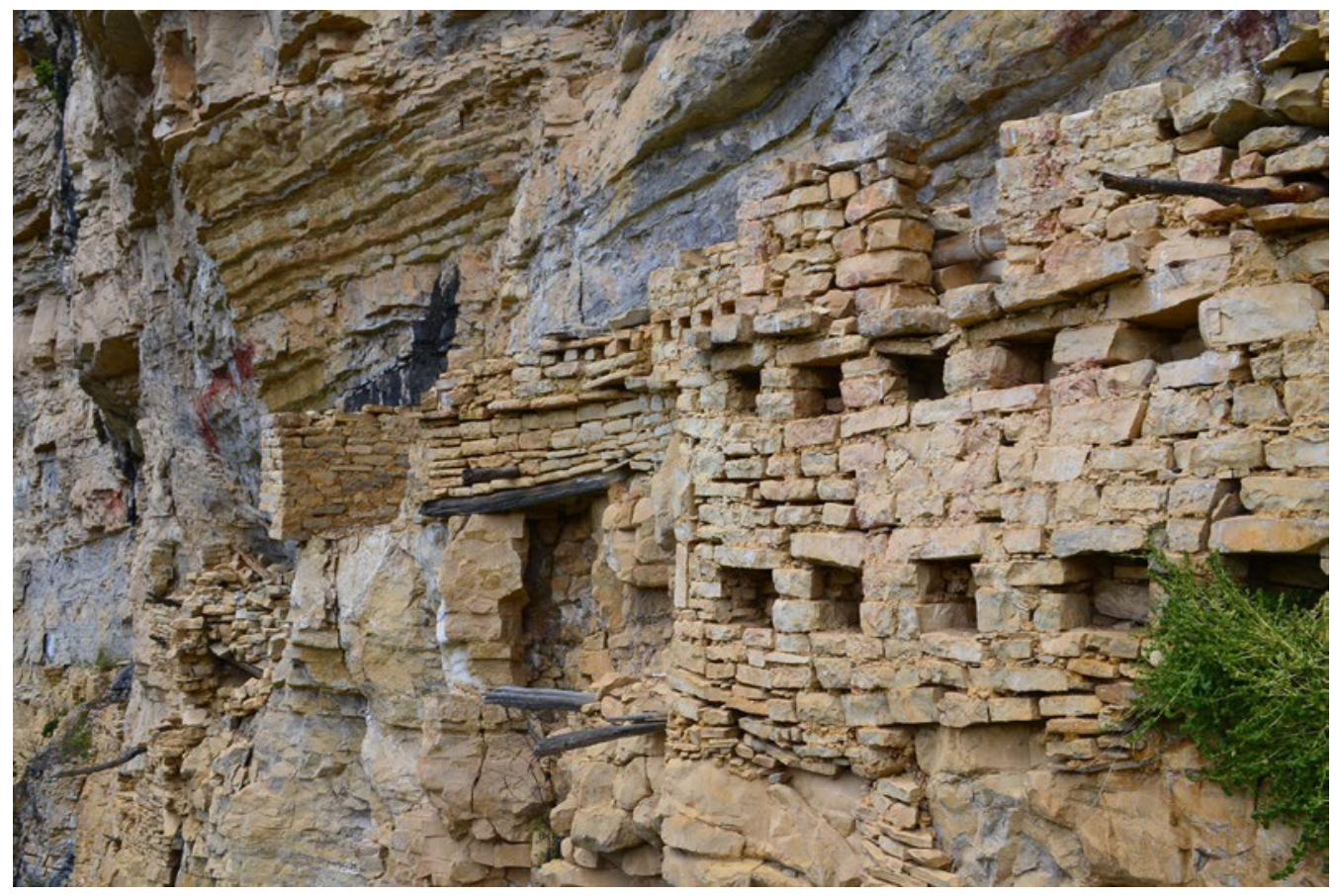

Figura 8. Foto de la chullpa Sur EF-29 mostrando los detalles de la fachada exterior de la plataforma con diez nichos pequeños.

\begin{tabular}{|c|c|c|c|c|c|c|}
\hline Estructuras & \multicolumn{2}{|c|}{ Sector Superior } & \multicolumn{2}{|c|}{ Sector Sur } & \multicolumn{2}{|l|}{ Total } \\
\hline Tumba individual & 0 & $0.0 \%$ & 0 & $0.0 \%$ & 0 & $0.0 \%$ \\
\hline Tumba colectiva & 9 & $36.0 \%$ & 3 & $3.0 \%$ & 10 & $8.0 \%$ \\
\hline Mausoleo (sobre repisa) & 3 & $12.0 \%$ & 10 & $10.0 \%$ & 12 & $9.6 \%$ \\
\hline Chullpa (con plataforma) & 5 & $20.0 \%$ & 20 & $20.0 \%$ & 25 & $20.0 \%$ \\
\hline Nicho natural & 2 & $8.0 \%$ & 1 & $1.0 \%$ & 3 & $2.4 \%$ \\
\hline Abrigo natural & 1 & $4.0 \%$ & 0 & $0.0 \%$ & 1 & $0.8 \%$ \\
\hline Caverna & 1 & $4.0 \%$ & 2 & $2.0 \%$ & 3 & $2.4 \%$ \\
\hline Base de la plataforma & 0 & $0.0 \%$ & 21 & $21.0 \%$ & 21 & $16.8 \%$ \\
\hline Muralla & 0 & $0.0 \%$ & 1 & $1.0 \%$ & 1 & $0.8 \%$ \\
\hline Desconocido & 4 & $16.0 \%$ & 42 & $42.0 \%$ & 49 & $39.2 \%$ \\
\hline Total & 25 & & 100 & & 125 & \\
\hline
\end{tabular}

Tabla 1. Distribución de las principales categorías de arquitectura identificadas en La Petaca. 


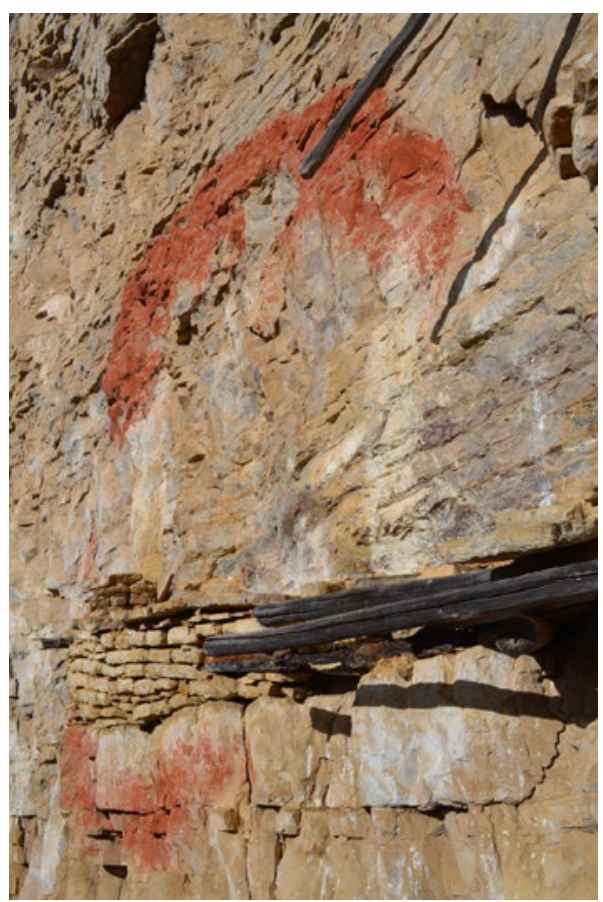

Figura 9. Foto de una gran área de pintura roja sobre la piedra superior de las estructuras mortuorias (cerca Sur EF-47).

encima de las estructuras también pueden haber contribuido al derrumbe de los muros. Los huecos picoteados sobre el acabado de arcilla de varias tumbas demuestran otras formas en la que las aves pueden haber sido responsables por la destrucción de estos restos.

Parece que existían más estructuras en este sitio, pero las repisas y estructuras pueden haber colapsado, caído, o sido destruidas por la caída de piedra debido a los procesos naturales de tafonomía y la actividad tectónica (v.g. terremotos, los cuales son comunes en la región), los cambios en la precipitación, o el movimiento animal.

Finalmente, es necesario explicar que la mayor parte del daño observado en estas estructuras es probablemente debido a la intervención humana, en tiempos antiguos y recientes. Aunque es difícil de acceder al sitio, se sabe que ha sido visitado en varias ocasiones por investigadores (Muscutt, comunicación personal) y equipos de videograbación con el propósito de explorar el acantilado, los cuales dejaron señales de daños evidentes. Pero el hecho más significativo fue el saqueo sistemático del sitio en décadas anteriores, con el propósito de encontrar momias y otros vestigios de valor para venderlos en el mercado negro. La gente local cuenta sobre los numerosos fardos funerarios que fueron recolectados cuando las tumbas fueron saqueadas, un proceso que también incluyó el daño de la arquitectura. Algunas momias moderadamente preservadas supuestamente provenientes de La Petaca están almacenadas en el Museo Regional de Chachapoyas, pero su procedencia exacta es desconocida (Fig. 10). Los restos observados y recolectados durante nuestra investigación son solo una fracción muy pequeña de lo que pudo haber existido en La Petaca originalmente.

\subsection{Sectores}

Subdividimos La Petaca en cuatro sectores principales con estructuras antropogénicas: Superior, Norte, Central y Sur. Nuestras investigaciones se enfocaron en los sectores Superior (SUP) (amarrillo) y Sur (SUR) (blanco) (Fig. 2), pero varias estructuras han sido observadas en los sectores Norte y Central, aunque estas todavía no se han estudiado en detalle. Existe una pared rocosa expuesta en la parte inferior del sector Sur, pero ninguna estructura es fácilmente visible. En el sector Superior observamos 22 tumbas antropogénicas y tres cavernas en dos repisas naturales angostas, las cuales 


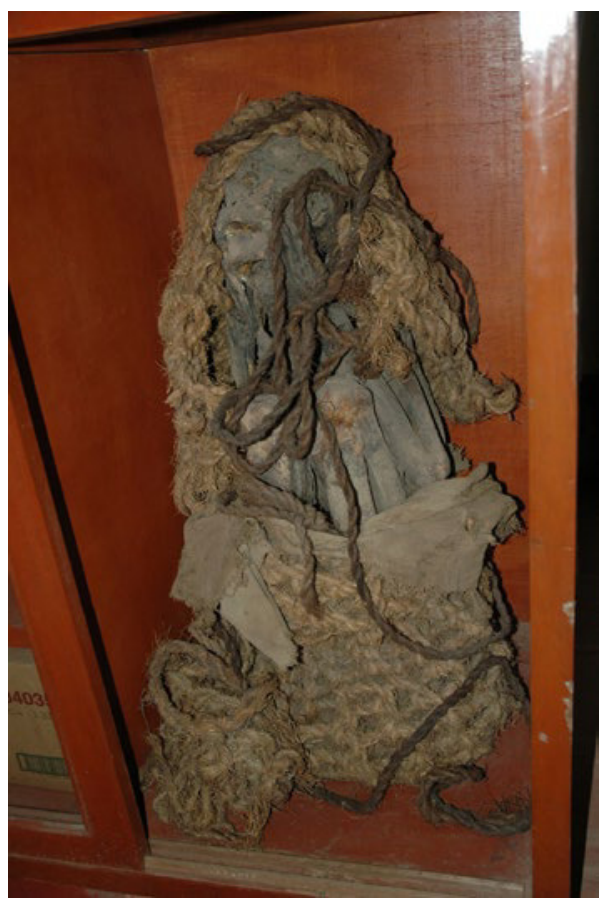

Figura 10. Foto de una momia descrita como recuperada de La Petaca en la década de 1990. Reside actualmente en el Museo Gilberto Tenorio Ruiz de Chachapoyas. (Permiso del Dirección Desconcentrada de Cultura Amazonas, Ministerio de Cultura).

son accesibles caminando con apoyo de sogas. El sector Sur contenía una cueva grande y 99 estructuras antropogénicas, distribuidas a lo largo de en seis repisas naturales. Nosotros accedimos a estas repisas caminando por el borde más bajo y ascendiendo por medio de sistemas de tres sogas adheridas a diferentes puntos de la pared de piedra, de modo que se pudiera tener acceso a estructuras localizadas en las partes altas de la pared (Fig. 3). Estas repisas generalmente miden menos de un metro de ancho, pero algunas de las respisas naturales aparentan haber sido modificadas en la antigüedad para así soportar mejor las tumbas más grandes. Aunque solo enfocamos nuestra investigación en los sectores Superior y Sur, no parece existir diferencia entre ellos con respecto a la variación arquitectónica o ubicación de las estructuras encimas de las repisas (tampoco aparenta ser significativamente diferente de los sectores inexplorados Norte y Central). No hay evidencia de que ningún área del sitio hubiera sido utilizada como residencia; no se recuperó evidencia de hábitat, áreas de actividad o cocina, o almacenamiento en ninguna de las estructuras.

\subsection{Cuevas y nichos}

En La Petaca hay por lo menos siete cavernas (grandes), abrigos y nichos (pequeños), que fueron utilizados como depósitos mortuorios. Aunque estos espacios son naturalmente delimitados, en muchos casos se han modificado construcciones y asociaciones tales como muros u otras estructuras completas (o destruidas). De estos contextos, cuatro aparentan estar completamente abiertos; no fue recuperada ninguna evidencia de construcciones previas que sellaran las entradas. En el sector Superior, se observó una cueva, SUP CF-01 (Fig. 4), la cual mide aproximadamente 3 metros de largo por 3 metros de ancho y 4 metros de altura en el punto más profundo, y tenía un depósito bien denso de restos humanos mezclados con un número mínimo de 55 individuos, incluyendo restos tanto de adultos como jóvenes. SUP CF-02, también en el sector Superior, es un colgante pequeño con una cueva poco profunda y de acceso difícil debido a una entrada restringida. Este contexto contenía un mínimo de 22 individuos, incluyendo adultos y jóvenes, descubiertos justo afuera de la entrada. Aquí también se encontraron restos de estructuras mortuorias (piedras trabajadas y mortero) que aparentaban haber sido desarmadas y quemadas. Estos contextos están descu- 
biertos en el punto norte de la repisa más baja en el sector Superior. Evidencia fotográfica demuestra que otros nichos pequeños ( -50 centímetros) naturales fueron sellados usando piedras de diferentes tamaños y mortero, e incluyen un dintel de madera en el borde superior de la entrada sellada.

El sector Sur contiene una cueva grande de forma triangular con tres entradas naturales observables desde el lado opuesto del valle. Denominada SUR CF-01, fue excavada con una serie de pozos de cateo en áreas con evidencia de concentración de restos humanos mezclados (Fig. 5). La inspección superficial y las excavaciones recuperaron restos representando un mínimo de 35 individuos, adultos y juveniles, así como pequeños fragmentos de cerámica, mates, textiles, cuentas de concha y restos animales. Recuperamos todos los materiales ubicados en la superficie y excavamos tres pozos en las zonas de alta concentración de huesos. Uno de estos pozos (50 por 50 centímetros) se ubicó en la boca de la caverna hacia el norte y los dos otros (50 por 100 centímetros cada uno), hacia el centro de la caverna. En cada pozo llegamos al nivel estéril pasando los 30 centímetros de profundidad. Se observó algo de variación dentro de esta cueva ya que algunos de los restos humanos se ubicaban dentro de nichos pequeños y repisas, mientras que otros se encontraban en el piso. Pero desafortunadamente el contexto estaba muy removido, con evidencia de saqueos modernos y la deposición original de los restos no se pudo recuperar.

$\mathrm{Al}$ norte de esta cueva, siguiendo la repisa tres, se encuentra una caverna cerrada con un muro (piedra trabajada y mortero) y con una entrada mirando hacia el oeste (pequeña y rectangular en medio del muro), identificada como SUR EF-26 (Fig. 12a). El derrumbe de piedras dentro de esta caverna dañó y cubrió cualquier material arqueológico encontrado dentro de esta estructura y es posible que haya sido saqueada antes de esta caída. A pesar de esto, sigue siendo un ejemplo clave en La Petaca de la construcción de muros con entradas para sellar una caverna. SUR EF-69 es un nicho natural, el cual también fue sellado con piedra, pero este muro ha sido parcialmente destruido y el nicho es accesible otra vez y actualmente está vacío, sin restos arqueológicos (Fig. 12b). Desafortunadamente, debido a su ubicación es muy difícil de acceder a él por lo que no se pudo explorar.

\subsection{Estructuras mortuorias}

Las estructuras mortuorias en este sitio demuestran una variación increíble en arquitectura (forma, tamaño, técnicas y decoración), pero los métodos y materiales de construcción son generalmente consistentes. Los materiales de construcción incluyen mampostería de piedras trabajadas y generalmente rectangulares (varios tamaños), vigas de madera de tamaño moderado (aprox.10 centímetros de diámetro), tablones grandes de madera (más de 1 metro de largo), mortero y acabado de arcilla y paja, y pinturas minerales de color rojo y blanco. Las piedras provienen del mismo acantilado y son el resultado de fracturas controladas de la piedra caliza. Tenemos evidencia de una posible cantera en un área del sitio con martillos de piedra (Fig. 11). Se observó un área donde grandes bloques de piedra fueron desmontados y retirados en la primera repisa SUR. No recuperamos evidencia de la producción del mortero o acabado de yeso, ni de cómo este material fue transportado a las construcciones en las repisas. Las estructuras que tuvieron un acabado de yeso tienen una superficie plana y no se observan improntas de dedos o manos en el yeso. Al mismo tiempo, ninguna de las estructuras tiene forma cilíndrica como las plataformas residenciales de los chachapoya, ni tampoco se observan los frisos y motivos comunes que han sido identificados en sitios mortuorios y residenciales (Schjellerup et al. 2003); aunque los sitios residenciales cercanos de La Joya y Monte Viudo claramente tienen estos diseños en su arquitectura (Guengerich 2014). Todas las estructuras en La Petaca usaron piedra modificada y mortero para la construcción de plataformas y cámaras funerarias, pero los tamaños de estas piedras varían grandemente hasta dentro de la misma estructura. La mayoría de los muros crean esquinas con ángulos casi perfectos de 90 grados. La única excepción son las estructuras más irregulares, las cuales siguen el contorno de la repisa angosta en la que fueron construidas. Algunas veces se utilizaron piedras más grandes para crear las esquinas y bordes usando piedras más pequeñas como relleno irregular dentro del muro. Algunas bases y plataformas fueron 


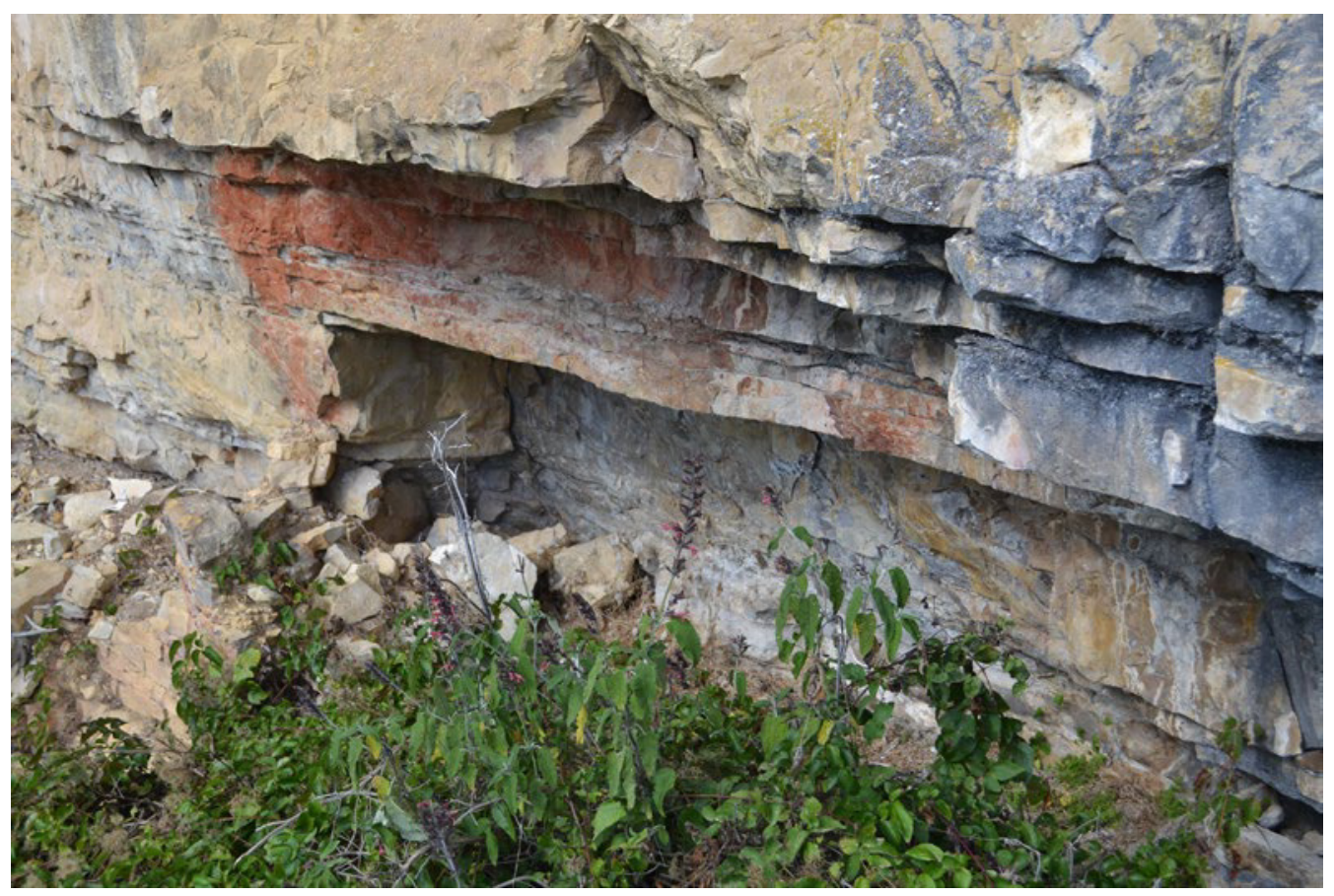

Figura 11. Foto de una posible cantera de piedra para uso constructivo de las tumbas.

creadas utilizando piedras de tamaños regulares y organizadas en niveles o capas; mientras que otras fueron creadas usando una mezcla de diferentes tamańos de piedra colocadas sin niveles obvios, pero creando un muro plano (Fig. 5).

Las cámaras funerarias de los mausoleos y las chullpas fueron construidas con tres muros artificiales y la pared natural de la piedra como el último muro. Siempre incluyen un vano de acceso en uno de los muros, normalmente rectangular, pero no más grande de 50 centímetros de ancho por 60 centímetros de alto. El grosor de los muros no varía mucho entre 35 y 40 centímetros, pero las dos fachadas, interna y externa, son bastante planas.

Algunas estructuras tienen superficies exteriores que están acabadas y aplanadas con yeso y han sido pintadas; otras solo tienen los restos de yeso y otras no tienen evidencia de un acabado de yeso y las piedras y el mortero fueron pintados directamente (Fig. 7; Tabla 2). Estos acabados decorativos no están relacionados con el nivel de artesanía de la construcción, y algunas de las estructuras mejor construidas en La Petaca no tienen evidencia de acabado de yeso (Fig. 8). Hasta existe una gran variación en las estructuras adyacentes. Además de la diversidad en los muros y las plataformas, las cornisas, los nichos, las ventanillas, los vanos de acceso, y los techos utilizan diferentes técnicas de construcción, incorporan piedra y madera, y tienen varios grados de elaboración. Un ejemplo es la estructura SUR EF-29, la cual tiene dos niveles paralelos de cinco nichos pequeños (un promedio de solamente 18 por 20 centímetros) en la fachada exterior. Los nichos son básicamente cuadrados y de tamaños iguales (Fig. 8). En este momento no existe evidencia de que objetos hubieran sido colocados dentro de ellos.

En La Petaca se presentan tres categorías principales de estructura funeraria: tumbas colectivas en forma colmena, chullpas y mausoleos (Tabla 1). Los vanos de acceso de estas estructuras varían extremadamente. Mientras que las tumbas colectivas no tienen puntos de acceso, las chullpas y los mausoleos sí los tienen. Las entradas a estas tumbas varían por el sitio, con algunas mirando hacia el norte, otras hacia el sur y muchas que miran directamente opuestas a la pared, hacia el oeste. Estas entradas variadas pueden haberse creado a causa de las restricciones de su acceso o pueden haber 


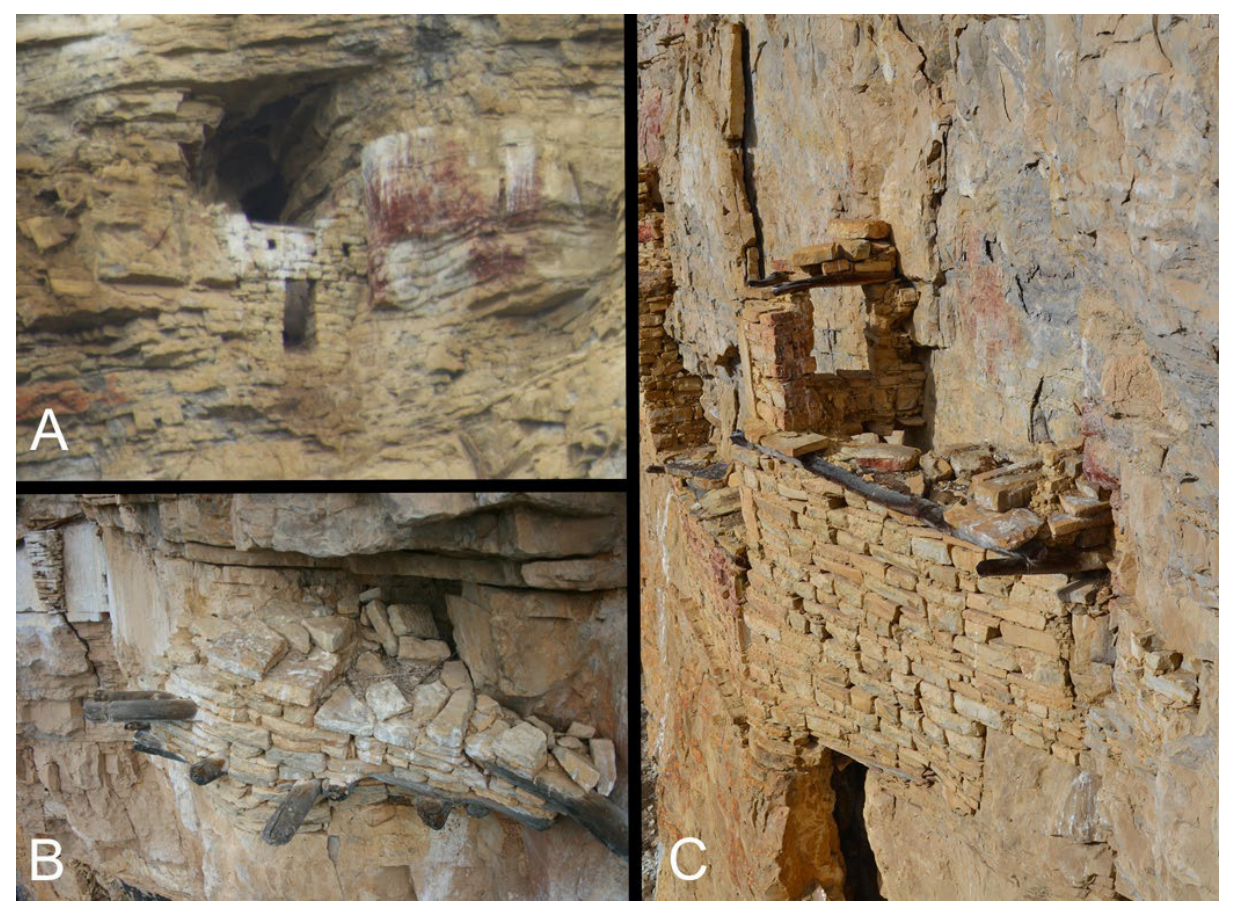

Figura 12. Fotos de la variación arquitectónica mortuoria. a. Sur EF-26, una caverna media encerrada con albañilería y dos vano de acceso. b. Sur EF-69, un nicho natural donde la muralla constructiva de albañilería está medio destruida. c. Sur EF-19, vista desde el sur demostrando la plataforma constructiva sobre el contorno natural de la repisa angosta, pero la cámara superior está destruida.

tenido un significado más simbólico, apuntando el campo visual de estas estructuras hacia otros sitios en el panorama. En este momento no poseemos suficientes datos para apoyar una interpretación sobre la otra.

Las tumbas colectivas de forma colmena en este sitio son similares a aquellas que se encuentran en otros sitios arqueológicos chachapoya como Kuélap, donde contienen los restos óseos de varios individuos dentro de un espacio circular o rectangular completamente cerrado, y en promedio tienen un diámetro de 1 a 2 metros. En Kuélap, este tipo de tumbas fueron ocupadas con entierros (individuos sentados con sus miembros flexionados), poniendo lajas de piedras entre ellos. Aunque aquellas tumbas encontradas en Kuélap generalmente tienen forma de colmena, las tumbas colectivas de La Petaca varían en la forma de sus bases (todas fueron desmontadas) entre circulares o rectangulares, frecuentemente utilizando la cornisa de la piedra como techo. Se encuentran más a menudo en el sector Superior que en el sector Sur.

Las chullpas fueron definidas como mausoleos construidos encima de una plataforma artificial. Puede ser que este estilo de estructura sea más frecuente en La Petaca debido a la necesidad de llenar grietas y crear plataformas artificiales en las cuales se pudiera construir una estructura. Sin embargo, esta no es la única razón de construir chullpas, algunas se encuentran adyacentes a mausoleos en una repisa de fácil acceso. Definimos los mausoleos como estructuras mortuorias cuadrangulares con tres muros cruzándose en ángulos de 90 grados y utilizando la pared de piedra natural. Se observaron tres mausoleos en el sector Superior y nueve en el sector Sur, de los cuales por lo menos cinco tenían dos niveles constructivos - y así dos cámaras funerarias- (Fig. 7). En general, son de planta rectangular, pero debido a los límites naturales de las repisas, a veces toman una forma redondeada o irregular. 


\begin{tabular}{|c|c|c|c|c|}
\hline \multicolumn{2}{|l|}{ Hallazgo } & \multicolumn{2}{|l|}{ Diferentes tipos } & $\begin{array}{c}\text { Número total } \\
\text { de estructuras } \\
\text { observadas }\end{array}$ \\
\hline \multirow{2}{*}{$\begin{array}{l}\text { Organización } \\
\text { de albañilería }\end{array}$} & Niveles regulares & Niveles irregulares & Sin niveles & \multirow{2}{*}{65} \\
\hline & $70.8 \%$ & $16.9 \%$ & $12.3 \%$ & \\
\hline
\end{tabular}

\begin{tabular}{|c|cr|r|rr|c|}
\hline $\begin{array}{c}\text { Decoración } \\
\text { superficial } \\
\text { external }\end{array}$ & $\begin{array}{c}\text { Pintura sobre la } \\
\text { albańilería }\end{array}$ & Mortero solo & $\begin{array}{c}\text { Pintura sobre } \\
\text { mortero }\end{array}$ & 25 \\
\hline
\end{tabular}

\begin{tabular}{|c|c|c|c|c|c|c|}
\hline \multirow{2}{*}{$\begin{array}{c}\text { Dintel del vano } \\
\text { de acceso }\end{array}$} & \multicolumn{2}{|c|}{ Madera } & \multicolumn{2}{|c|}{ Piedra } & \multirow{2}{*}{ - } & \multirow{2}{*}{5} \\
\hline & 2 & $40.0 \%$ & 3 & $60.0 \%$ & & \\
\hline
\end{tabular}

\begin{tabular}{|c|cc|c|cr|c|}
\hline $\begin{array}{c}\text { Evidencia de } \\
\text { pintura roja }\end{array}$ & \multicolumn{2}{|c|}{$\begin{array}{c}\text { Sobre la fachada de } \\
\text { la estructura }\end{array}$} & \multicolumn{2}{|c|}{$\begin{array}{c}\text { Superior de la } \\
\text { estructura }\end{array}$} & Petroglifos & 36 \\
\hline
\end{tabular}

\begin{tabular}{|c|c|c|c|c|c|c|c|}
\hline \multirow[t]{2}{*}{ Cornisa } & \multicolumn{2}{|c|}{ Solo techo superior } & \multicolumn{2}{|c|}{ Solo intermedio } & \multicolumn{2}{|c|}{$\begin{array}{c}\text { Ambos superior y } \\
\text { intermedio }\end{array}$} & \multirow[t]{2}{*}{16} \\
\hline & 0 & $0.0 \%$ & 13 & $20.0 \%$ & 3 & $4.6 \%$ & \\
\hline
\end{tabular}

Tabla 2. Resumen de frecuencia de elementos decorativos y hallazgos arquitectónicos de La Petaca.

Las estructuras presentan diferentes niveles de manufactura. Podemos evaluar la calidad de manufactura de estas construcciones basados en la elaboración de la piedra, la calidad de los restos de mortero y/o pintura, la aproximación a ángulos rectos y la uniformidad de la construcción que son consistentes con la teoría de la inversión (Tainter 1978). Calificamos categóricamente la manufactura de las estructuras como pobre, moderada, o buena basados en la eficacia de los patrones de construcción ( $v$.g., tamaño y regularidad de la mampostería, alineación y orientación que sean consistentes, aplanado del acabado). Basados en el análisis de 65 estructuras en las cuales la mampostería pudo ser evaluada calificamos $8(12 \%)$ como pobres, 11 (17\%) como moderadas, y $46(71 \%)$ con buena calidad de construcción y arquitectura. Sin embargo, la calidad constructiva no tiene relación con la ubicación de la estructura en el sitio. También descubrimos varios casos en los cuales un edificio de poca calidad fue construido adyacente a uno de excelente calidad, como es evidente en las estructuras SUP EF-14 y SUP EF-15 (Fig. 6).

Finalmente, estas estructuras son pequeñas comparadas con las estructuras residenciales, y claramente fueron limitadas por la geografía del sitio. En general varían de longitud entre uno y tres metros, con un promedio de 2,09 metros, pero el ancho es limitado por las respisas angostas, las cuales restringen esta dimensión a menos de 1 metro de promedio. La altura de la tumba también estuvo limitada por la geología, generalmente por la saliente de la misma piedra, pero la estructura más alta (la más completa) (SUR EF-16) mide un poco más de 3 metros de alto. Algunos mausoleos y chullpas muestran dos niveles constructivos, pero la mayoría solo consisten en uno. Algunas estructuras tienen evidencia de haber tenido pisos superiores incompletos y/o derrumbados. 


\subsection{Plataformas y caminos}

No todas las construcciones parecen haber tenido propósitos funerarios. En nuestras observaciones originales, interpretamos estas plataformas como caminos de tránsito, los cuales extendían las repisas naturales para simplificar la travesía del espacio mortuorio, conectando las estructuras y áreas donde la repisa natural era demasiado angosta. Es claro que el acceso para la construcción y enterramiento fue horizontal a través de las repisas naturales y no vertical, usando sogas o escaleras. Después de un análisis más profundo, estos caminos aparentan ser uno de los pasos más tempranos del proceso de construcción requerido para ampliar la repisa natural y crear la superficie sobre la cual se construiría la tumba (Fig. 12a). La construcción de estas plataformas independientes es un logro de ingeniería que no tiene igual en esta región. ¿Por qué no usar solo las repisas naturales o las superficies planas? La construcción de muchas de estas plataformas requirió la introducción de palos de madera en grietas o espacios en la pared que sobresalieran de manera perpendicular, así después había que reforzarlos con piedra y mortero, y finalmente añadir lajas de piedra para crear una base estable, aunque un poco angosta. Muchas de estas plataformas todavía se preservan a pesar de la fractura y erosión de la piedra. Se necesita más investigación, ya que muchos de los «muros» y «caminos» se encuentran al medio de grandes espacios desolados sin manera de acceso (Fig. 12b). Impresiona la habilidad de estos antiguos arquitectos, aunque mucha de la evidencia de otras estructuras y plataformas ha sido borrada por el tiempo. Sin embargo, no observamos evidencia de destrucción intencional de estas plataformas que pudiera sugerir que los antiguos habitantes de la zona intentaron prevenir el acceso a estas estructuras.

\subsection{Cronología}

La cronología de las estructuras representó todo un reto debido a la dificultad de acceso, la variación en preservación del material orgánico y la falta de confiabilidad de los fechados de radiocarbono para el Horizonte Tardío en esta región. La fecha de radiocarbono más temprana correspondió a la tumba SUP EF-13, indicando una construcción durante la última parte del Horizonte Medio $\sim 950$ d.C. (Tabla 3). Esta tumba es una de las estructuras de mejor calidad en construcción, pero no tiene acabado de yeso, ni fue pintada. Otros contextos en el sector Sur (SUR CF-01 y SUR EF-18) fueron fechados al Período Intermedio Tardío y el Horizonte Tardío, sugiriendo que el espacio mortuorio fue utilizado durante por lo menos 600 años y refleja uso y construcción a largo plazo en el sitio. Las pocas fechas recolectadas de varias estructuras alrededor del sitio complican la interpretación de que los cambios en arquitectura y el uso de espacios funerarios reflejaran cambios hacia mayor complejidad a través del tiempo. La caverna natural en el sector Superior (SUP CF-01), con su abundancia de restos humanos, resultó con una fecha de radiocarbono temprana (1190-1270 d.C. [calib.]), pero es un punto intermedio entre las otras fechas, lo cual sugiere que los espacios naturales fueron usados al mismo tiempo que las tumbas más elaboradas. No recuperamos evidencia de uso específico inka de estos espacios (cerámico o textiles) para apoyar una ocupación significativa durante el Horizonte Tardío ${ }^{1}$, y no existe evidencia que claramente defina una explicación del abandono del sitio (más que el colonialismo europeo).

\subsection{Análisis preliminar de los restos humanos}

El análisis bioarqueológico de los restos humanos recuperados indica el enterramiento de una gran diversidad de individuos de todas las edades y los dos sexos. Una gran variedad de condiciones patológicas fue identificada en cada uno de los contextos en los que se registraron restos humanos (Gonzáles Valencia y Toyne 2014). Generalmente los restos estuvieron desarticulados y aislados. Mientras que se recuperó alguna evidencia de restos momificados de individuos casi completos en posición flexionada con capas de textiles, el saqueo extenso de estos contextos nos impide la interpretación de estos restos para entender si fueron depósitos primarios, o si también existieron procesos secundarios como los observados en la Laguna de los Cóndores (Guillén 2002; Buikstra y 


\begin{tabular}{lcccc}
\hline \multicolumn{1}{c}{ Sector } & Contexto & Edad convencional & Rango de calibración de 2 Sigma & Beta \\
\hline Superior & EF-13 (paja en mortero) & $1040+/-30 \mathrm{BP}$ & d.C. $900-1030$ & 369482 \\
Superior & Caverna 1 (hueso humano) & $800+/-30 \mathrm{BP}$ & d.C. $1190-1270$ & 369478 \\
Sur & Caverna 1 (hueso humano) & $450+/-30 \mathrm{BP}$ & d.C. $1420-1460$ & 369479 \\
Sur & EF-18 (paja en mortero) & $380+/-30 \mathrm{BP}$ & d.C. $1440-1630$ & 369480 \\
\hline
\end{tabular}

Tabla 3. Fechas radiocarbónicas de las estructuras de diferentes partes de La Petaca.

Nystrom 2003). Aunque las cavernas presentan una gran mezcla de los restos, análisis del material recuperado sugiere que esos contextos fueron utilizados para entierros primarios y no como osarios secundarios (Epstein y Toyne 2015).

La mayoría de los restos analizados se originaron de contextos mezclados y fueron examinados elemento por elemento, en vez de por entierros completos. En general no había muchos restos en cada contexto, sino en las cavernas naturales. En la mayoría de los casos, el número mínimo de individuos (NMI) presente en un contexto fue caracterizado por el número de fémures o calcáneos del mismo lado, o fracciones de cráneos (Tabla 4). Pero, por ejemplo, en caso de SUR EF-18, estimamos un mínimo de 8 personas, pero fueron representados por solamente 35 fragmentos óseos. Restos de subadultos así como de adultos fueron identificados en casi todos los contextos, con la mayoría de los restos representando adultos. Estos resultados son consistentes con otros estudios que han registrado pocos restos de subadultos (Bracamonte 2002; Guillén 2002; Toyne y Narváez este número).

El sexo de los individuos solo se puede definir utilizando la pelvis o el cráneo, así que el NMI y el número total de restos identificados por sexo no son idénticos. En La Petaca, la representación de restos masculinos y femeninos es bastante similar con un total de 42 hombres (54\%) y 36 mujeres (46\%) (Tabla 4). Este patrón se identifica en los dos sectores investigados, así como en cada contexto. Es claro entonces que los contextos funerarios no fueron utilizados para diferenciar o separar a los individuos enterrados por sexo o por edad. Análisis más extenso y detallado de los restos humanos se presentará en un próximo artículo.

\section{Discusión}

En general, estos nuevos datos nos prestan información sumamente valiosa sobre la importancia de los espacios mortuorios y la complejidad regional de los chachapoya. La Petaca probablemente es uno de los complejos mortuorios más reconocidos en la región, pero hasta ahora se sabía muy poco de él, solo se tenían descripciones e interpretaciones de una de las pinturas rupestres antropomórficas (Muscutt 1987, 1998). En un solo sector de la escarpadura identificamos más de 100 estructuras antropogénicas con propósito funerario, y aunque la mayoría tiene evidencia de daños tafonómicos (procesos humanos y naturales), este análisis detallado demuestra que las investigaciones arqueológicas no se pueden hacer de lejos. La experiencia personal de acceder a estas tumbas también provee una perspectiva valiosa de campo, de vista y de su relación con otros restos arqueológicos además de la naturaleza de estar en este ambiente vertical (Figs. 14 y 15). Nuestra evaluación sobre la dificultad de acceso a estos espacios se basa en la suposición del miedo que siente una persona moderna a las alturas y a la caída de piedras. Aunque a nosotros nos pareciera excesivamente difícil caminar por las repisas angostas resbalándonos en las piedras, los antiguos chachapoya a lo mejor no encontraron los mismos desafíos, ya que habrían crecido y vivido moviéndose a través de estos espacios. Pero esto nos presenta una pregunta interesante, ¿quiénes fueron los constructores, y quién transportó los cuerpos - fueron especialistas, o pudieron participar o acceder estas tumbas todos en la comunidad durante rituales repetitivos para mantener contacto con los ancestros sagrados enterrados en 


\begin{tabular}{|l|cccc|cc|}
\cline { 2 - 7 } \multicolumn{1}{c|}{} & \multicolumn{4}{c|}{ Adultos } & \multicolumn{2}{c|}{ Subadulto } \\
\hline Estructura & $\begin{array}{c}\text { Posiblemente } \\
\text { masculino }\end{array}$ & $\begin{array}{c}\text { Posibilemente } \\
\text { femenino }\end{array}$ & $\begin{array}{c}\text { Sexo } \\
\text { indeterminado }\end{array}$ & $\begin{array}{c}\text { Total de } \\
\text { adulto }\end{array}$ & $\begin{array}{c}\text { Sexo } \\
\text { indeterminado }\end{array}$ & Total \\
\hline Sup CF -01 & 14 & 19 & 10 & 43 & 12 & 55 \\
Sup CF -02 & 7 & 5 & 4 & 16 & 6 & 22 \\
Sup EF-14 & 2 & 0 & 0 & 2 & 0 & 2 \\
Sup EF-15 & 0 & 0 & 0 & 0 & 0 & 0 \\
Sur EF - 01 & 2 & 1 & 2 & 5 & 3 & 8 \\
Sur EF - 13 & 4 & 3 & 0 & 7 & 1 & 8 \\
Sur EF - 16 & 0 & 0 & 0 & 0 & 0 & 0 \\
Sur EF - 18 & 2 & 1 & 1 & 4 & 4 & 8 \\
Sur EF -19 & 1 & 0 & 0 & 1 & 1 & 2 \\
Sur CF - 01 & 10 & 7 & 8 & 25 & 10 & 35 \\
\hline Total & 42 & 36 & 25 & 103 & 37 & 140 \\
\hline
\end{tabular}

Tabla 4. Número mínimo de individuos (NMI) de los restos recuperados en los contextos investigados en los sectores Superior y Sur diferenciados por edad y sexo (de adultos).

La Petaca? Es imposible responder a esta pregunta definitivamente. Desde esta perspectiva, la variación en los métodos de construcción, dirección y ubicación nos presenta nuevas interpretaciones y una investigación más detallada de la arquitectura de los espacios mortuorios.

$\mathrm{Si}$ incluimos los espacios naturales, como las cuevas, la variación en este sitio se extiende desde espacios sin modificar hasta tumbas completamente artificiales, con diferentes niveles de elaboración. Las estructuras más complejas incluyen niveles bien organizados de piedra uniforme, dinteles de piedra y nichos, lo que implica mayor planificación y técnicas especializadas, aunque sigan un plan estándar de construcción y diseño. Esta variación no es de esperarse en este complejo tan grande, especialmente si se compara con los pocos sitios mortuorios que han sido investigados, como Los Pinchudos, Revash o Laguna de los Cóndores (von Hagen y Guillén 1998) (Fig. 16). Estos otros sitios aparentan representar un proceso de diseño y construcción más consistente o restringido, cronológicamente o socialmente (un único grupo trabajando en conjunto o un único diseño arquitectónico). También, en general, son más fáciles de acceder con pocas estructuras grandes. Sin embargo, el gran número de individuos enterrados en cada estructura de estos otros sitios y la gran gama de edades y distribución de sexos demuestra un patrón de entierro similar al de La Petaca. Estos mausoleos colectivos grandes no fueron restringidos a un grupo demográfico específico, pero de seguro sí fueron limitados por clase social. Se puede proponer un estatus elevado de un individuo enterrado en Los Pinchudos, Laguna de los Cóndores y Laguna Huayabamba a partir de la elaboración de las tumbas y su decoración (más que lo observado en La Petaca), pero también en la calidad de los materiales asociados, incluyendo cerámicas extranjeras, objetos de intercambio a larga distancia y la calidad excepcional de los textiles (Muscutt 1998; Morales Gamarra 2002; Guillén et al. 2011). Desafortunadamente, en comparación, en La Petaca no recuperamos evidencia de este tipo de productos exóticos debido al saqueo. Sin embargo, la diversidad en la elaboración de las construcciones sugiere que, a lo mejor existía una variedad de estatus socioeconómicos — v.g., acceso al trabajo o material para la construcción de tumbas en La Petaca-. Esto sugiere que varios grupos de la comunidad con diferentes estatus sociales construyeron estructuras y enterraron a sus muertos en este sitio.

Tanto los espacios naturales como los espacios construidos fueron utilizados de modo parecido en este sitio, y no se demostró ninguna relación entre la ubicación y la arquitectura. Sin embargo, algunas características comunes incluyen la forma rectangular, vanos de acceso rectangulares, 

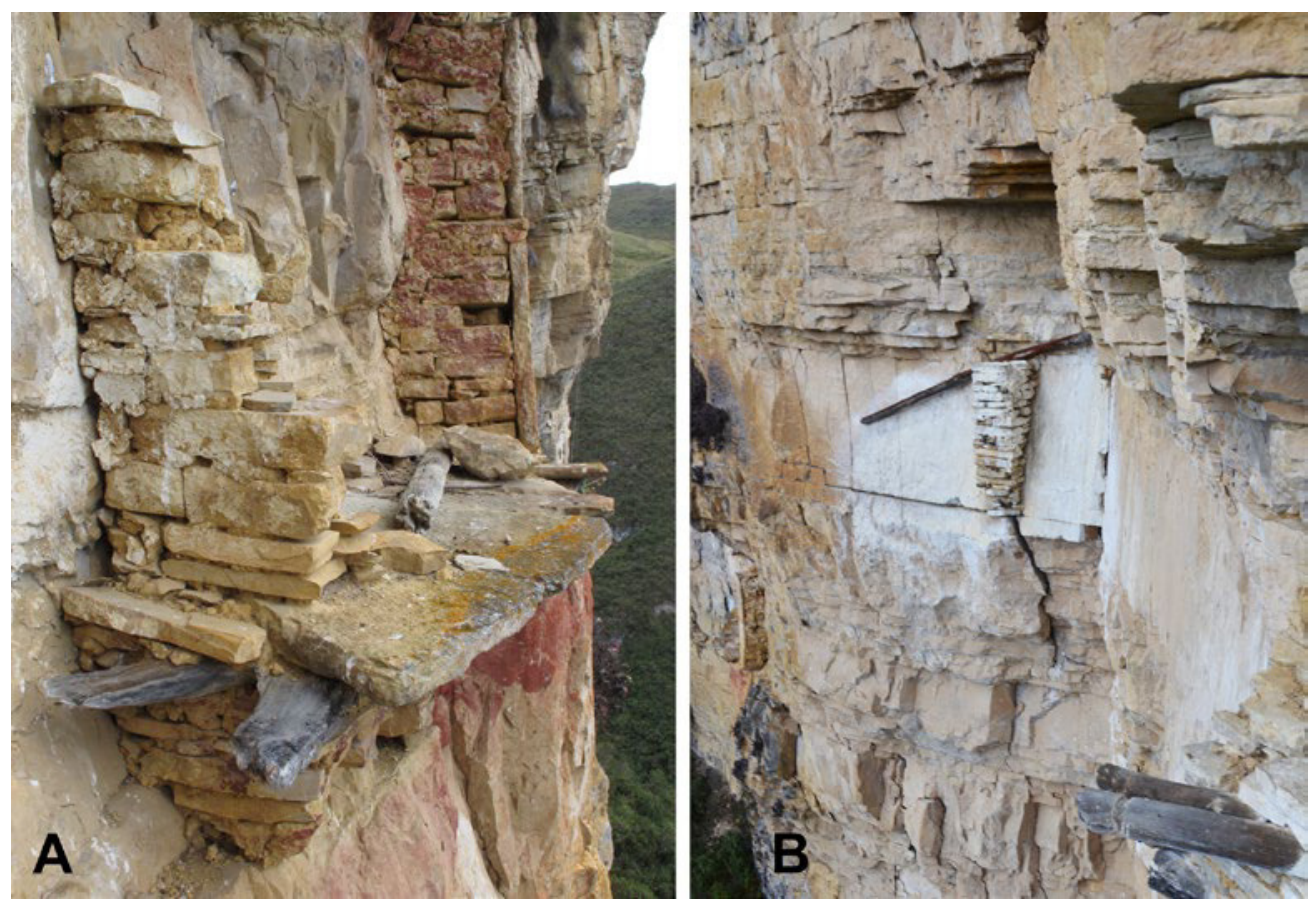

Figura 13. Fotos de construcciones mortuorias únicas. a. Sur EF-71 bajo construcción, incluyendo una plataforma de lajas con vigas de madera integrados horizontalmente y la muralla norte incompleta de piedra con mortero de la cámara. b. Una construcción de origen desconocido. Parece una muralla sobre una fachada de piedra plana sin repisa asociada; quizás representa una nueva estructura y la manera de establecer nuevas plataformas sin repisas.

mortero de arcilla, piedra local y patrones de pintura similares (para esas estructuras que tenían pintura). Estas características sugieren que: 1) el estilo arquitectónico funerario fue adaptado a la ubicación precaria debido a las limitaciones de transporte de material y labor; 2) hubo poco cambio a través de las épocas (aunque se requieren más fechas para obtener mejor resolución); y 3) aparentan reflejar una tradición cultural sin influencia directa exterior.

La diversidad en estilos, hasta dentro de cada categoría, es mayor de lo que se espera con una sola ocupación, período, o sociedad sin diferenciación social (DeMarrais 2007). Existen demasiados variables para suponer que fueron creadas por un solo artesano o bajo un paradigma de construcción unificado; existen tumbas simples y rústicas al igual que exactas y elaboradas.

Aun así, la variación en la manufactura y la arquitectura y el uso de los espacios naturales puedan reflejar diferencias mínimas de estatus entre los individuos enterrados aquí (Abrams 1989; Arhem 1998). Esas familias o grupos sociales con acceso a mano de obra, mejores artesanos, o recursos tenían más posibilidad de producir tumbas de mejor calidad y más elaboradas incluyendo acabados de yeso y pintura. Comparado con otras regiones de los Andes y más allá (Carmean 1991; Bolaños 2010; Velasco 2014), la elaboración de estas tumbas debe ser considerada un indicador importante de una mayor inversión en las prácticas funerarias de individuos, sobre la base de su valor social y el acceso de sus sobrevivientes a las riquezas para construir tumbas más elaboradas (Tainter 1978). Otra posibilidad es que esta variación refleje la identidad social de aquellos que construyeron las tumbas, sea cual fuera el caso, una misma ideología atrajo a estos diversos grupos a usar el mismo espacio funerario sagrado para sus entierros; construyendo, regresando, reusando y anexando estructuras a lo largo un gran período de tiempo (Isbell 1997; Lovell 1998; Nystrom et al. 2010).

Las tumbas colectivas y aquellas estructuras adyacentes a otras pueden reflejar unidades familiares, linajes, o filiaciones sociales que preferían entierros cerca a sus familiares o ancestros 


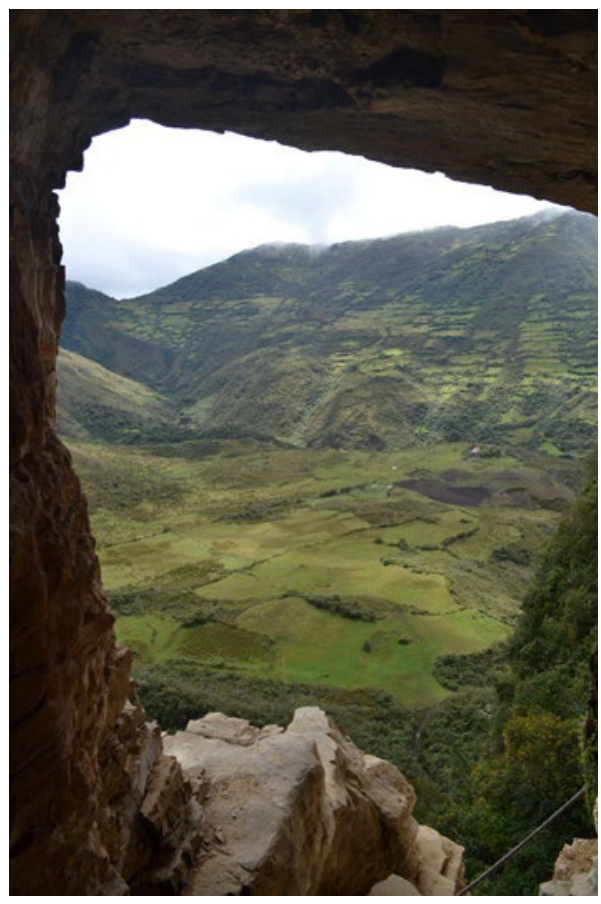

Figura 14. Vista al oeste desde la entrada central de Sup CF-01.

(Zuidema 1973). Desafortunadamente, la mayoría de los acabados exteriores y los contenidos de estas estructuras (especialmente las ofrendas y textiles) han sido perdidos debido al saqueo y los procesos tafonómicos naturales de este ambiente geológico inestable. Lo que sí queda claro es que estas estructuras no pudieron haber sido construidas por un solo individuo o un grupo cerrado de especialistas ya que la variación encontrada sería mucho menos pronunciada (Parker Pearson y Richards 1994), así que la normalización y especialización de nivel estatal no está presente en el diseńo constructivo de los espacios mortuorios de La Petaca. Esto sugiere que no hubo un liderazgo centralizado en la creación de este sitio, sino que la variación observada es independiente y se debe a las disparidades en habilidad y agencia del artesano y el acceso al material. La discusión sobre la naturaleza de la complejidad social de los chachapoya sugiere que eran comunidades autónomas, más que unificadas bajo un liderazgo de élite centralizado (Church y von Hagen 2008; Schjellerup 2008; y ver capítulos en este número). Los caciques locales tenían acceso al poder de decisión, pero es posible que en las prácticas mortuorias no se plasmaran esas diferencias en el acceso al poder social o político, que sí fueron evidentes en el caso de estados andinos contemporáneos como los moche o los sicán, donde los líderes controlaban grandes recursos, los cuales se veían reflejados en la ubicación privilegiada de sus tumbas y las riquezas con las que fueron enterrados (Donnan 1995; Moore 1996; Shimada et al. 2004; Shimada et al. 2015). Estudios recientes de Guengerich $(2014 ; 2015)$ sobre la arquitectura residencial sugieren que los chachapoya se concentraban en las estructuras residenciales individuales más que en los espacios comunes, pero trabajaban debajo del canon cultural de arquitectura e iconografía. Por eso, las tumbas de La Petaca y su variación no reflejan jerarquía social, sino heterarquía social (DeMarrais 2007; Herrera 2007). Así, estos contextos mortuorios crearon un panorama social unificado de identidad y creencias chachapoya.

Los cambios a través del tiempo podrían explicar un poco esta variación, pero las pocas fechas de radiocarbono no nos permiten una mejor resolución de la cronología del sitio. Los lugares naturales y fáciles de acceder fueron utilizados al mismo tiempo que las tumbas más complejas y de difícil acceso, lo que significa que la manera de colocar a los muertos no fue restringida socialmente solo a aquellos con recursos para construir en este lugar. Es probable que la comunidad entera colaboró para crear este espacio mortuorio. La ubicación de esta fachada de piedra con relación a 


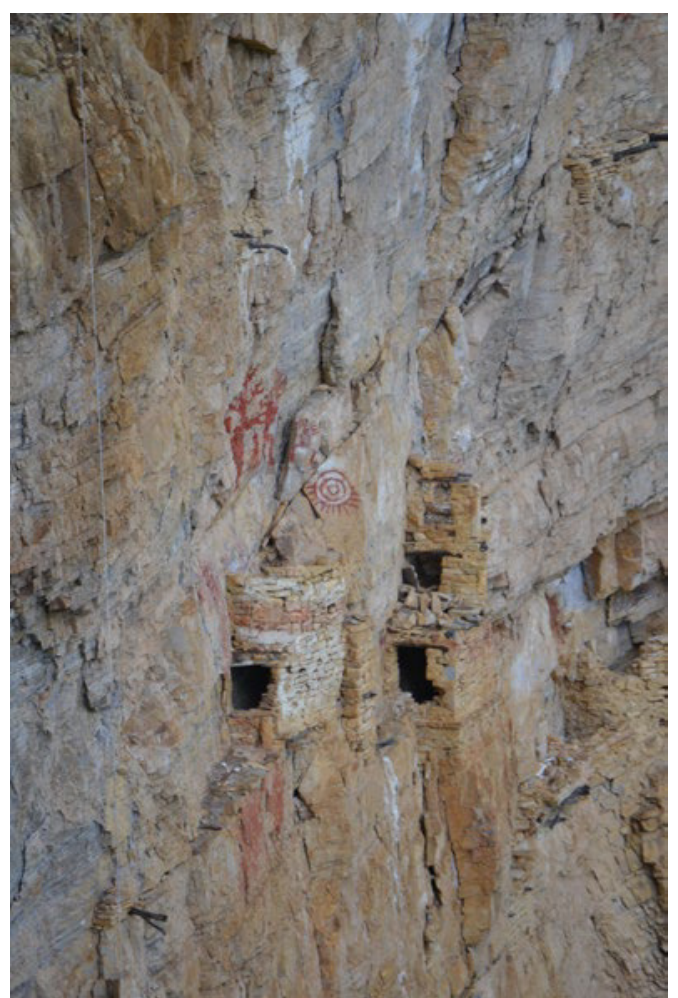

Figura 15. Foto estructuras mortuorias sobre el sector Sur de vista desde el norte demostrando los vanos de acceso de Sur EF-18 y EF-19.

otros sitios en el área, como Monte Viudo, La Bóveda, y La Joya ( $c f$. Guengerich 2014) nos permite inferir que estas comunidades seguramente contribuyeron en esta tarea (Fig. 14). Las fechas de La Petaca son consistentes con la ocupación principal de Monte Viudo (Guengerich 2014). Pero se necesitan más investigaciones en estos sitios para entender sus historias ocupacionales y su conexión con este espacio mortuorio.

\section{Conclusión}

Este estudio detallado de La Petaca nos presta la oportunidad de entender mejor las prácticas mortuorias de los antiguos chachapoya y refleja la contribución positiva del uso de los complejos mortuorios (hasta aquellos que han sido saqueados), al estudio de la organización social (GerdauRadonic y Herrera 2010). Observamos una gama de variación muy amplia en el tipo de construcción funeraria y en sus características arquitectónicas, aunque los materiales y métodos son bastante consistentes. Ninguna estructura demostró una calidad o complejidad decorativa que sugiriera diferenciación social extrema y la evidencia cronológica no apoya la interpretación de cambios en uso entre espacios naturales y espacios construidos a través del tiempo. Claramente, el número absoluto de las estructuras confirma el uso a largo plazo del sitio, pero también resalta la gran población regional que participó en la construcción y en el mantenimiento de este espacio sagrado.

La Petaca es el complejo mortuorio más grande en la región hasta ahora conocido, y más análisis son necesarios para recolectar la mayor cantidad de datos antes que el sitio desaparezca por completo. La Petaca está ubicado geográficamente entre varios sitios ocupaciones incluyendo Monte Viudo y otros que permanecen hasta ahora sin estudiar. Este sitio presenta, además, una cronología de más que 600 años, lo que sugiere que su complejidad mortuoria y tamaño pueden representar tanto aspectos culturales como históricos. Este proyecto tiene objetivos de largo plazo con los cuales se puede mejorar la resolución cronológica de los diferentes estilos de tumbas para así 


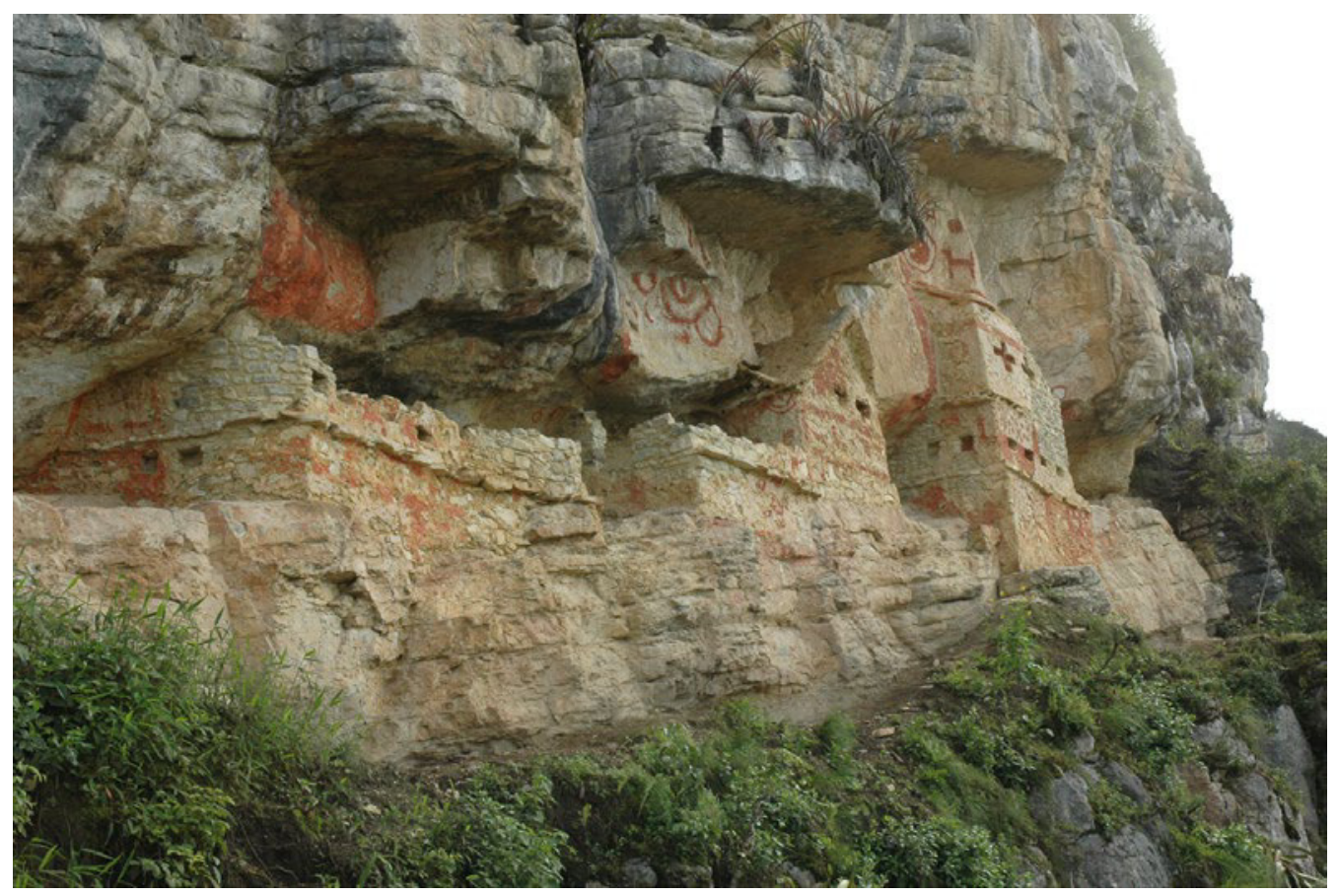

Figura 16. Foto de las estructuras mortuorias de Revash, sector $C$.

comprender su construcción, la vida y muerte de sus «habitantes» y el abandono eventual del sitio. Así podremos entender mejor este espacio sagrado chachapoya y su conexión con las comunidades cercanas a través la variación mortuoria regional.

\section{Agradecimientos}

Este trabajo fue patrocinado por la Fundación Petzl (Francia), MonVertical (Perú) y el Departamento de Antropología y el Colegio de Ciencias de la Universidad de Florida Central (EE.UU.). Este proyecto no hubiera sido posible sin el apoyo logístico y técnico de la Asociación Ukhupacha y la Universidad Jaume I (España) y su equipo, incluyendo a Salvador Guinot, Jordi Puig, Ismael Mejía, Felipe Sancristán, Milan Saez, Javi Sanz, Ińaki Menkatorre y Patric Vogel. La investigación arqueológica no hubiera sido posible sin el permiso del Ministerio de Cultura de Perú, y la colaboración de Daniel «Danny» Gonzales, Willy Chiguala, Manuel Malaver, Lori Epstein y Daisy Ańazco. También queremos agradecer a las autoridades locales de Leymebamba y su Comunidad Campesina, y específicamente a varios individuos incluyendo doña Nelly y don Julio de la Casona de Leymebamba, el señor Hitler Mori, señor Javier Farje, don Florentino Ruiz, don Senecio Garro y doña Rubitsa Rojas. Disfrutamos mucho el simposio y la discusión durante la conferencia de Society for American Archaeology (SAA) con los otros participantes de este volumen. Un agradecimiento especial a Warren Church y Anna Guengerich por organizar y editar esta contribución importante a la historia de Chachapoyas. Y finalmente un gran reconocimiento al revisor anónimo por sus sugerencias y su comentario, y a Cecilia Mauricio por su labor editando este volumen.

\section{Notas}

${ }^{1}$ Aunque material reportado como saqueado de La Petaca aparentemente incluye una abundancia de cerámica inka como aríbalos (Keith Muscutt, comunicación personal 2015). 


\section{REFERENCIAS}

\section{Abrams, E. M.}

1989 Architecture and energy: an evolutionary perspective, en: M.B. Schiffer (ed.), Archaeology method and theory, 47-87, University of Arizona Press, Tucson.

Arhem, K.

1998 Power of place: landscape, territory and local belonging in northwest Amazonia, en: N. Lovell (ed.), Locality and belonging, 78-102, Routledge, London.

Arriaza, B. T., M. Doubrava, V. G. Standen y H. Haas

2005 Differential mortuary treatment among the andean chinchorro fishers: social inequalities or in situ regional cultural evolution?, Current Anthropology 46(4), 662-671.

Binford, L. R.

1971 Mortuary practices: their study and their potential, Memoirs of the Society for American Archaeology 25, 6-29.

Bolaños, A.

2010 El reto vertical Andino: desafíos de la gravedad en las sociedades Andinas precoloniales, Arqueología y Sociedad 21, 119-129.

Bracamonte, F.

2002 Los Pinchudos: un estudio preliminar de su población, Sian 12, 14-15.

\section{Briceño, J. y K. Muscutt}

2004 Fardos funerarios chachapoya en la Laguna Huayabamba, Sian 9(15), 6-7.

Brown, J. A.

1971 The dimensions of status in the burials at Spiro, Memoirs of the Society for American Archaeology 25, 92-112.

\section{Buikstra, J. E. y K. C. Nystrom}

2003 Embodied traditions: the Chachapoya and Inca ancestors, en: R. Jeske y D.K. Charles (ed.), Theory, method and practice in modern archaeology, 29-48, Praeger Press, London.

\section{Carmean, K.}

1991 Architectural labor investment and social stratification at Sayil, Yucatan, Mexico, Latin American Antiquity 2(2), 151-165.

Carr, C.

1995 Mortuary practices: their social, philosophical-religious, circumstantial, and physical determinants, Journal of Archaeological Method and Theory 2(2), 105-200.

Church, W. B. y A. von Hagen

2008 Chachapoyas: cultural development at an Andean cloud forest crossroads, en: H. Silverman y W.H. Isbell (ed.), The handbook of south American archaeology, 903-926, Springer, New York.

\section{Crandall, J. M.}

2012 Chachapoya eschatology: spaces of death in the northern Andes, Baessler-Archiv 60, 1-17.

DeMarrais, E.

2007 Settings and symbols: assessing complexity in two pre-Hispanic polities, en: S. Kohring y S. Wynne-Jones (ed.), Socialising complexity: Approaches to power and interaction in the archaeological record, 118-139, Oxbow Books, Oxford.

Dillehay, T. D.

1995 Tombs for the living: Andean mortuary practices, Dumbarton Oaks Research Library and Collection, Washington, D.C.

Donnan, C. B.

1995 Moche funerary practice, en: T.D. Dillehay (ed.), Tombs for the living: Andean mortuary practices, 111-160, Dumbarton Oaks Research Library and Collection, Washington, D.C. 
Epstein, L. y J. M. Toyne

2015 When space is limited: a spatial exploration of pre-Hispanic Chachapoya mortuary and ritual microlandscape, en: A. Osterholtz (ed.), Theoretical approaches to analysis and interpretation of commingled buman remains, 95-124, Springer, New York.

Espinoza Soriano, W.

1967 Los señoríos étnicos de Chachapoyas y la alianza Hispano-chacha: visitas, informaciones y memoriales inéditos de 1572-1574, Revista Histórica (Lima) 30, 224-333.

Gerdau-Radonic, K. y A. Herrera

2010 Why dig looted tombs? Two examples and some answers from Keushu (Ancash Highlands, Peru), Bulletin et Memoires de la Societe de'Anthropologie de Paris 22(3-4), 145-156.

Gil, N.

1936 Las tumbas esculturales de Aispachaka, Boletín de la Sociedad Geográfica de Lima 53, 235-239.

González Valencia, D. y J. M. Toyne

2014 Prospección e investigación de contextos arqueológicos y funerarios del sitio arqueológico de La Petaca (PALP), Informe Final entregado al Ministerio de Cultura de Peru.

Guengerich, A.

2014 The architect's signature: the social production of a residential landscape at Monte Viudo, Chachapoyas, Peru, Journal of Anthropological Archaeology 34, 1-16.

2015 Settlement organization and architecture in Late Intermediate Period Chachapoyas, northeastern Peru, Latin American Antiquity 26, 362-381.

Guillén, S. E.

2002 Las momias de Laguna de los Cóndores, en: E. González y R. León (ed.), Chachapoyas, el reino perdido, 345-387, AFP Integra, Lima.

Guillén, S. E., P. Lerche y E. Guevara

2011 Chacha motivos en el Museo Leymebamba, Centro Mallqui, Leymebamba.

von Hagen, A.

2002 Chachapoya iconography and society at Laguna de los Cóndores, Perú, en: H. Silverman y W.H. Isbell (ed.), Andean archaeology II: art, landscape, and society, 137-155, Plenum Publishers, New York.

von Hagen, A. y S. Guillén

1998 Tombs with a view, Archaeology 51(2), 48-54.

Hastorf, Christine A.

2003 Community with the Ancestors: ceremonies and social memory in the Middle Formative at Chiripa, Bolivia, Journal of Anthropological Archaeology 22, 305-332.

Herrera, A.

2005 Las kanchas circulares: espacios de interacción social en la Sierra Norte del Perú, Boletín de Arqueología PUCP 9, 233-255.

2007 Social landscapes and community identity: the social organization of space in the North-Central Andes, en: S. Kohring y S. Wynne-Jones (ed.), Socialising complexity: Structure, interpretation and power in archaeological discourse, 161-185, Oxbow Books, Oxford.

Isbell, W. $\mathrm{H}$.

1997 Mummies and mortuary monuments, University of Texas Press, Austin.

Jakobsen, J., J. B. Jorgensen, L. K. Jorgensen, y I. R. Schjellerup

1986 "Cazadores de cabezas» en sitios pre-Inca de Chachapoyas, Amazonas, Revista del Museo Nacional 48, 139-185.

Kamp, K. A.

1998 Social hierarchy and burial treatments: a comparative assessment, cross-cultural research, Cross-Cultural Research 32(1), 79-115.

Kauffmann, F. y G. Ligabue

2003 Los chachapoya(s): moradores ancestrales de los Andes Amazónicos, Universidad Alas Peruanas, Lima. 
Koschmieder, K. y C. Gaither

2010 Tumbas de guerreros chachapoya en abrigos rocosos de la provincia de Luya, Departamento de Amazonas, Arqueología y Sociedad 22, 1-30.

Lefebvre, $\mathrm{H}$.

1991 The production of space, Blackwell Publishing Ltd, London.

Lovell, N.

1998 Locality and belonging, Psychology Press, London/New York.

Mantha, A.

2009 Territoriality, social boundaries and ancestor veneration in the Central Andes of Peru, Journal of Anthropological Archaeology 28, 158-176.

Moore, J. D.

1996 Architecture and power in the ancient Andes: the archaeology of public buildings, Cambridge University Press, Cambridge/New York.

Morales Gamarra, R.

2002 Los Pinchudos, arquitectura funeraria en río Abiseo, San Martin: Parte I, Arkinka 76, 92-101.

Muscutt, K.

1987 A trophy head pictograph from the Peruvian Amazon, en: K. Hedges (ed.), Rock Art Papers, 155-160, San Diego Museum Papers, San Diego.

1998 Warrior of the clouds: a lost civilization in the upper Amazon of Peru, University of New Mexico Press, Albuquerque.

Nystrom, K. C., J. E. Buikstra y K. Muscutt

2010 Chachapoya Mortuary Behavior: A Consideration of Method and Meaning, Chungara 42(2), 477-495.

Parker Pearson, M. y C. Richards

1994 Architecture and Order: Approaches to Social Space, Routledge, London/New York.

Reichlen, H. y P. Reichlen

1950 Rechereches archeologiques dans les andes du haut Utcubamba, Journal de la Société des Americanistes 39, 219-246.

Ruiz Estrada, A.

2009 Sobre las formas de sepultamiento prehispanicas en Kuélap, Amazonas, Arqueología y Sociedad 20, 1-16.

Salomon, F.

1995 The beautiful grandparents: Andean ancestor shrines and mortuary ritual as seen through colonial records, en: T. Dillehay (ed.), Tombs for the living: Andean mortuary practices, 315-353, Dumbarton Oaks Research Library and Collection, Washington, D.C.

2015 Turbulent tombs, en: J. Fitzsimmons e I. Shimada (ed.), Living with the dead in the Andes, 329-347, University of Arizona Press, Tucson.

Saxe, A. A.

1971 Social dimensions of mortuary practices in a Mesolithic population from Wadi Halfa, Sudan, Memoirs of the Society for American Archaeology 25, 39-57.

Schjellerup, I. R.

2008 Sacando a los caciques de la oscuridad del olvido. Etnias Chachapoya y Chilcho, Bulletin de L'Institut Français d'Études Andines 37(1), 111-122.

Schjellerup, I.R., M. K.Sørensen, C. Espinoza, V. Quipuscoa y V. Peña

2003 Los valles olvidados: pasado y presente en la utilización de recursos en la ceja de selva, Perú, The National Museum of Denmark, Copenhagen.

Shimada, I., H. D. Klaus, R. A. Segura y G. Matsumoto

2015 Living with the dead. Conception and treatment of the dead on the Peruvian coast, en: J. Fitzsimmons e I. Shimada (ed.), Living with the dead in the Andes, 107-172, University of Arizona Press, Tucson.

Shimada, I., K.-i. Shinoda, J. Farnum, R. Corruccini y H. Watanabe

2004 An integrated analysis of pre-Hispanic mortuary practices: a middle Sican case study, Current Anthropology 45(3), 369-402. 
Tainter, J. A.

1978 Mortuary practices and the study of prehistoric social systems, Advances in archaeological methods and theory $1,105-141$.

Urton, G.

2001 A calendrical and demographic tomb text from northern Peru, Latin American Antiquity 12,127-148.

Velasco, M. C.

2014 Building on the ancestors: mortuary structures and extended agency in the Late Prehispanic Colca Valley, Peru, Cambridge Archaeological Journal 24, 453-465.

Zuidema, T.

1973 Kinship and ancestor cult in three Peruvian communities: Hernan Principes's account of 1622, Bulletin de l'Institut Francais d'Etudes Andines 2, 16-33.

Fecha de recepción: 30/05/2016

Fecha de aceptación: 07/02/2017 